
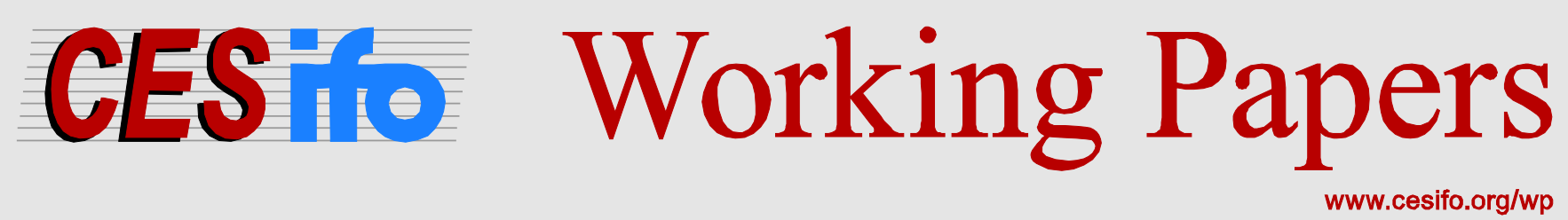

\title{
The Exchange Rate Susceptibility of Some European Core Industries and the Currency Union
}

\author{
David Leuwer \\ Bernd Süssmuth
}

\author{
CESIFO WORKING PAPER NO. 4253 \\ CATEgory 7: MONETARy POLICY AND INTERNATIONAL FinANCE \\ MAY 2013
}

An electronic version of the paper may be downloaded

- from the SSRN website:

- from the RePEc website:

- from the CESifo website:

WwW.SSRN.com

Www.RePEc.org

www.CESifo-group.org/wp

\section{CESifo}




\title{
The Exchange Rate Susceptibility of Some European Core Industries and the Currency Union
}

\begin{abstract}
This paper investigates the relationship between real exchange rate changes and the German, French and UK automobile and mechanical engineering sector. In stylized models, exports decline whenever the domestic currency appreciates and vice versa. Strategic firm behavior, however, can obscure the unambiguousness of this relationship, rendering the impact of a strengthening Euro on exports and on overall order volume unclear. To quantify the impact of the EUR/USD real exchange rate on German and French key exporting industries, we estimate a trivariate VAR based on monthly data from 1995 to 2010, respectively. We proceed analogously with the GBP/USD rate and the UK automobile and mechanical engineering sector series. Our findings indicate that an appreciating Euro hampers exports in the German and French core sectors, but does not cause these industries "pain" in the sense of an aggravated business climate. The latter does not apply to the respective time series for the UK. Time varying parameter VAR estimates confirm this immunization for members in the period after installation of the currency union.
\end{abstract}

JEL-Code: C300, E420, F410.

Keywords: exporting sectors, confidence indicators, time varying parameter VAR.

\author{
David Leuwer \\ Institute for Empirical Research in \\ Economics \\ University of Leipzig \\ Grimmaische Str. 12 \\ Germany-04109 Leipzig \\ david.leuwer@uni-leipzig.de
}

\author{
Bernd Süssmuth \\ Institute for Empirical Research in \\ Economics \\ University of Leipzig \\ Grimmaische Str. 12 \\ Germany-04109 Leipzig \\ suessmuth@wifa.uni-leipzig.de
}

We thank Marco Sunder, Alfred Maussner, Jan-Egbert Sturm, Alex Rathke, and participants of the Macro and Financial Econometrics Conference at Heidelberg University, the DIW-FU Berlin Macroeconometric Workshop, the Conference on Recent Developments in Macroeconomics at ZEW Mannheim, the biannual Centre for International Research on Economic Tendency Surveys (CIRET) Conference in Vienna, the Economics Lunchtime Seminar at the University of Leipzig, the Economics Research Seminar at the University of Augsburg, and the International Economic Policy Seminar at the University of Zurich for many valuable comments and suggestions. 
"The Euro should not fluctuate according to the mood of the markets. A monetary zone must have an exchange rate policy ... If not, we are insisting on countries making efforts to be competitive which are destroyed by the rising value of the Euro."

Francois Hollande (February 2013)

\section{Introduction}

Throughout the post-war period it is in particular the German economy that is widely regarded as depending on its exports. Public opinion sees exports as driving German -and ultimately also European- economic growth. Following this line of reasoning, key sectors such as the automobile and mechanical engineering industries are perceived as being especially susceptible to a sizable, continuing appreciation of the Euro. On the other hand, they arguably profit from a depreciating Euro. In this context, the EUR/USD exchange rate is one of the most intensely observed relationships. In 2003, for example, the US business of German companies is said to have been decreasing by ten percent due to a weak Dollar (Belke et al. 2009). As of the second half of the first decade of the 2000s it became popular to talk about a "pain threshold" for European companies with regard to the EUR/USD exchange rate. Prominently the term is used referring to a suffering of German and/or French export industries from a strengthening of the Euro beyond a certain threshold. Recently, even terms such as "strategic depreciation" and "currency wars" are used to refer to the fear of European industries to lose grounds in competitiveness against the backdrop of devaluating competitor countries; see the above quote of French president Francois Hollande. However, with regard to stock market returns Griffin and Stulz (2001), for example, find that common shocks to industries across countries are substantially more important than competitive shocks due to changes in exchange rates. According to their findings, weekly exchange rate shocks explain but a small fraction of the relative performance of industries and, in particular, also of sectors that produce internationally traded goods.

In our reading of the existing literature the question of the existence and dimension of the exchange rate susceptibility of European core industries has not been satisfyingly answered. Several studies investigate the EUR/USD exchange rate dynamics in general at the level of a nation or supranation. See, among others, Sinn and Westermann (2001), Fratzscher (2008), and Belke et al. (2009). Another strand of literature analyzes the 
issue of exchange rate susceptibility at the level of the firm or industry. Griffin and Stulz (2001), for example, investigate different sectors in the US, Canada, the UK, France, Germany, and Japan. As mentioned above, their results suggest that exchange rates play, if at all, only a minor role in determining sectoral performance. Contrary to Griffin and Stulz (2001), Bodnar and Gentry (1993) find significant exposure to exchange rate movements for industries in the US, Canada, and Japan. Williamson (2001) is a study that explicitly investigates the automobile industry finding, in general, significant exchange rate exposure for this sector. However, due to "lack of competition" Williamson excludes the German automobile industry from his analysis. Finally, Greenaway et al. (2010) emphasize the effects of exchange rate changes at a firm's cost side by noting that appreciation may have offsetting effects through relatively cheaper imported intermediate goods. Their empirical results for the UK manufacturing sector indicate that exchange rate dynamics might not have a significant effect at all once effects at the cost side are considered. Overall, there is no coherent picture of the EUR/USD exchange rate susceptibility of key exporting sectors of the core EU economies in the literature to back up the vast narrative evidence on the issue.

Here, we take a different route and define susceptibility more directly as an aggravation of both the sectoral order book indicators and of the business climate in the automobile and mechanical engineering industries. These two sectors account, for example, in the case of Germany for about one third of its total exports in 2011. ${ }^{1}$ Our central empirical strategy consists of estimating trivariate VAR models incorporating the real exchange rate, the volume index of exports from the two key exporting sectors, and sectoral confidence indicators using monthly data from 1995 to 2010. Against this backdrop, our study seeks to scrutinize three fundamental hypotheses:

- The popular belief of a profound exchange rate susceptibility of the core sectors, i.e. the automobile and mechanical engineering industries.

- The Williamson-hypothesis according to which the German economy and its key sector, the automobile industry, stand out (Williamson 2001).

- The Frankel-Rose-hypothesis according to which currency union members get immunized as the union fosters intra-Eurozone trade counteracting exchange rate

\footnotetext{
${ }^{1}$ Official statistics of traded goods and commodities as well as of trade partners of the German economy can be found at http://www.destatis.de.
} 
exposure (Frankel and Rose 2002).

To address the first issue we focus on the German economy as our benchmark case. Comparing our results to estimates obtained from French sectoral series then allows us to assess a possibly exceptional reaction of German key sectors. Finally, considering the GBP/USD exchange rate along with UK sectoral series we analyze whether the two currency union members witnessed some change in their response to exchange rate shocks over time.

The remainder of the paper is organized as follows: Section 2 gives some theoretical underpinning. In section 3, we use German series to estimate a reference case. Section 4 extends our reference case to French and UK time series. In section 5 we look at the sectoral response to an exchange rate shock over time. Finally, section 6 concludes.

\section{Theoretical Considerations}

In a stylized world as described in Appendix A.1 the reaction of exports and ultimately also of the business climate and other confidence indicators to changes in the real exchange rate in the exporting sectors is clear-cut. However, in a world of differentiated export goods supplied by firms on segmented markets that are characterized by imperfect competition the unambiguousness of this relationship gets lost. In the following, we briefly sketch how strategic firm behavior can affect the relationship between the real exchange rate, exports, and the business climate of exporting sectors in the presence of such market imperfections.

The relationship between the real exchange rate and the amount of exports outlined above assumes that export companies practice a full exchange rate pass-through. ${ }^{2}$ In reality this pass-through will typically be incomplete which is referred to as pricing-to-market (PTM) in the literature (Krugman 1986). It is assumed that companies set their export price according to $P=(1+\pi) M C$, i.e., due to some market power they mark-up price their products. ${ }^{3}$ PTM can be a possibility to conserve foreign market shares as it allows the exporter to stabilize supply prices in foreign currency by reacting to exchange rate

\footnotetext{
${ }^{2} \mathrm{~A}$ full pass-trough requires perfectly competitive markets. Incomplete competition implies incomplete and inert price adjustments.

${ }^{3}$ This mark-up (price discrimination) may vary among export destinations.
} 
movements with changes in the mark-up. Furthermore, PTM may help to avoid menu cost in case of exchange rate changes which are only transitory in nature. PTM might also serve as a "war chest," whenever firms believe that regaining forgone market shares is more costly than transitory losses from foregone profits. Several empirical studies have found evidence for PTM on the side of exporters in general (Knetter 1993, Falk and Falk 2000) and for companies in the automobile and mechanical-engineering industry in particular (Belke et al. 2009). Ultimately, the extent of exchange rate pass-through and PTM is an empirical question hinged on the price elasticity of exports. PTM may help to cushion negative externalities of an appreciation on the demand side, although it will always go at the cost of firms' profits. Certainly, the extent of the latter depends on the price elasticity of exports. For example, according to Deutsche Bundesbank (2008), German exports, in particular, to non-European economies, react rather weakly to exchange rate changes. ${ }^{4}$ If, for example, the domestic currency appreciates by $1 \%$ real exports are estimated to fall by only about $0.25 \%$. This is, at least partly, ascribed to the fact that relative price-inelastic goods make up a considerable share of German exports (for example, individualized investment goods such as specific machinery). Foreign customers may also stick to their supplier even though the value of foreign currency increases because of switching cost being even higher. As German companies are highly specialized in certain industries, "foreign consumers are 'caught' in their relation to German suppliers" (Belke et al. 2009).

Of course, there are also significant cost effects of an appreciation of the domestic currency. The price of imported intermediate goods declines when the domestic currency appreciates. This is a particularly important issue for European firms when it comes to paying the bill for energy used in the production of manufactured goods as Germany, France, and the UK are not among the major oil producing economies in the world.

One further strategy to cope with exchange rate risk is to shift production abroad. This so called "natural hedging" has been widely practiced by the German automobile industry in the past 15 years setting up production plants, particularly, in the US (e.g. BMW in Spartanburg, SC, in the US), but also recently in China (e.g. Volkswagen in Changchun and BMW in Shenyang). Similarly, Renault operates a production plant in Tanger, Morocco. Natural hedging assures that local buyers are supplied without any exchange rate risk. An additional advantage lies in the possibility of firms to compensate

\footnotetext{
${ }^{4}$ For the following arguments and figures see Belke et al. (2009).
} 
losses from lowered exports with cheaper imports from the foreign country within their company as the domestic currency appreciates.

A final caveat concerns the importance of intra-European trade. When investigating the EUR/USD exchange rate effect on the French or German business climate, one has to consider the role of other trading partners, in particular, intra-EU partners. The overall impact of a weak USD might be small, if forgone exports to the US can be compensated by trade with other (intra-EU) economies. Actually, the US is, for example, ranked third among the top trading partners of Germany in 2009. The list is headed by Europe and Asia: In 2009, 62\% of the German exports went to EU member states, of which 17 are also members in the common currency area, while many of the remaining ones have pegged their currencies to the Euro. The latter concerns in particular the Central and Eastern European trading partners. Of course, this bears the implication for Germany that most of its production and trade becomes independent of exchange rate changes. According to estimates reported in Frankel and Rose (2002), a currency union roughly triples trade with other union members.

\section{Empirical Assessment: The Case of Germany}

\section{$3.1 \quad$ Data}

Our baseline empirical analysis relies on a sample consisting of monthly data of the EUR/USD real exchange rate (EXR), German exports, measured as volume index of exports (EXP), and the business climate (BC) in the relevant sectors: the automobile industry and the mechanical engineering sector. The period of observation ranges from January 1995 to October 2010 covering 190 observations. Data on the (consumer price index (CPI) deflated) EUR/USD exchange rate are taken from the Pacific Exchange Rate Service provided by the University of British Columbia (http://fx.sauder.ubc.ca/data.html). The exchange rate is denoted in price notation, i.e., $x E U R / 1 U S D$. Hence, an increase of this ratio represents a depreciation of the Euro. Pre-1999 data (prior to Delors I) for the Euro are the official ECU basket rates rather than imputed pseudo rates. Export series of the German automobile and mechanical engineering industry are obtained from Eurostat. The data cover all German exports within the SITC (Standard International Trade Classification) system product-group 7 "Machinery and Transport Equipment" to the 
United States. Exports are measured in 100 kilograms. The series is normalized to January 1995 (=100). Our series of the business climate in the automobile and mechanical engineering sector are drawn from the detailed analysis of the "ifo-Geschäftsklimaindex," which is published on a monthly base by the ifo Institute. The index is calculated as the mean of balances of percentage shares of positive and negative judgements reported by the companies with regard to their current business situation and their business expectations in the following six months (CESifo 2010, p. 3). Thus, as many other indicators, $\mathrm{BC}$ is based on two variables (business situation and business expectations), which are measured on a three-point Likert scale capturing a good, equal or bad state. For the period from 2004 to 2010 the business climate is reported for unified Germany for the automobile industry and the mechanical engineering industry, respectively. We calculate a joint business climate for the two sectors by simply aggregating and taking means. Prior to 2004, the business climate in the two sectors is published for West Germany and East Germany separately. For West Germany the series of the mechanical engineering industry is subsumed under the sub-category "Investment goods without cars" (manufacturing sector), while the business climate of the automobile sector is classified under "Commodities" (manufacturing sector). For East Germany, we draw the business climate for the respective industries from the "Investment goods manufacturing industry" category. The business climate for Germany, taking East and West together, is calculated by aggregating and taking means. The series are shown in Appendix A.2, where also summary statistics are given in Table 1.

To judge whether one or all of the three series had to be seasonally adjusted, we used the variate difference method by Tintner et al. (1978). We find that our exports series (EXP) need to be seasonally adjusted. ${ }^{5}$ Seasonal adjustment of the EXP series is done using standard US Census Bureau X-12 ARIMA. In a next step, we perform ADF tests for all series. We set and determine the maximum number of lags $k_{\max }=\left[12(T / 100)^{1 / 4}\right]$, where $T$ denotes number of observations; here, $k_{\max }=14$. The optimal number of lags is chosen on the base of the AIC. The null of a unit root cannot be rejected at the $5 \%$-level of significance for the series EXR and EXP ( $p$-value equals 0.5927 and 0.5311 , respectively). ${ }^{6}$ We apply a Hodrick-Prescott filter (HP) with a smoothing weight of $\lambda=129,600$ (Ravn and Uhlig 2002) to both series and consider $\log$ first differenced ( $\log \mathrm{D}$ filtered) series

\footnotetext{
${ }^{5}$ Data on the business climate have been seasonally adjusted by the ifo Institute.

${ }^{6}$ The null of a unit root can be rejected at a $1 \%$-level of significance for BC (corresponding $p$-value $=0.0002$ ). Results are robust for different UR/stationarity tests such as the KPSS test.
} 
alternatively.

\subsection{Descriptive analysis: Correlation structure}

We start by looking at the inter-series dynamics in the time and frequency domain. A visual inspection of the correlation function $\mathbf{P}_{\mathbf{y}}(\tau)$ both for $\operatorname{HP}(129,600)$ and log first difference filtered series (not shown here) indicates a significant positive correlation between the series EXR and EXP as well as EXP and BC.

There is only little significant correlation between EXR and BC while there is evidence for significant cross-series dynamics between the exchange rate and exports on the one hand and exports and business climate on the other. This result is backed up and broadened by inspection of the cross-series dynamics in the frequency domain. ${ }^{7}$ We calculate several multivariate measures in the frequency domain. ${ }^{8}$ If one considers two stationary time series $x_{t}$ and $y_{t}$ the cross-spectrum between these two is given by

$$
f_{x y}(\omega)=c_{x y}(\omega)-i q_{x y}(\omega)
$$

with $\omega \in[-\pi, \pi]$. The cospectrum $c_{x y}(\omega)$ measures the "in-phase" covariance between the two series, whereas the quadrature spectrum $q_{x y}(\omega)$ measures the covariance between the "out-of-phase" components. Together with the series autospectra this can be used to calculate the squared coherency

$$
s c(\omega)=\frac{\left|f_{x y}(\omega)\right|^{2}}{f_{x}(\omega) f_{y}(\omega)},
$$

which is defined $0 \leq s c(\omega) \leq 1$. The squared coherency can be interpreted as a measure for the strength of the linear relationship between the two series at different frequencies. Unfortunately, the squared coherency does not contain information about a potential phase-shift, i.e. the lead-lag structure of the two series at different frequencies. This is why it should be interpreted jointly with the phase spectrum

$$
\phi_{x y}=-\arctan \left(q_{x y}(\omega) / c_{x y}(\omega)\right) .
$$

\footnotetext{
${ }^{7}$ The following common link exists between the time and frequency domain:

$f_{x}(\omega)=(1 / 2 \pi) \sum_{\tau=-\infty}^{\infty} \gamma_{x}(\tau) e^{-i \omega \tau}$ with $\omega \in[-\pi, \pi]$, i.e., the spectrum of a series is defined as the Fourier transform of the autocovariance function.

${ }^{8}$ See Appendix A.3 for a detailed development of measures.
} 
Alternatively, one may also judge the linear relationship between the two series by looking at the dynamic correlation

$$
\rho(\omega)=\frac{c_{x y}(\omega)}{\sqrt{f_{x}(\omega) f_{y}(\omega)}},
$$

with $-1 \leq \rho(\omega) \leq 1$. The dynamic correlation measures the correlation between the "inphase" components of $x_{t}$ and $y_{t}$ at frequency $\omega$ (Croux et al. 2001). Figure 1 shows the autospectra, integrated spectra, amount of explained variance and dynamic correlation computed from bivariate VARs fitted to our vector of observations $\boldsymbol{y}_{t}$ for the HP and $\log \mathrm{D}$ filtered series, respectively.
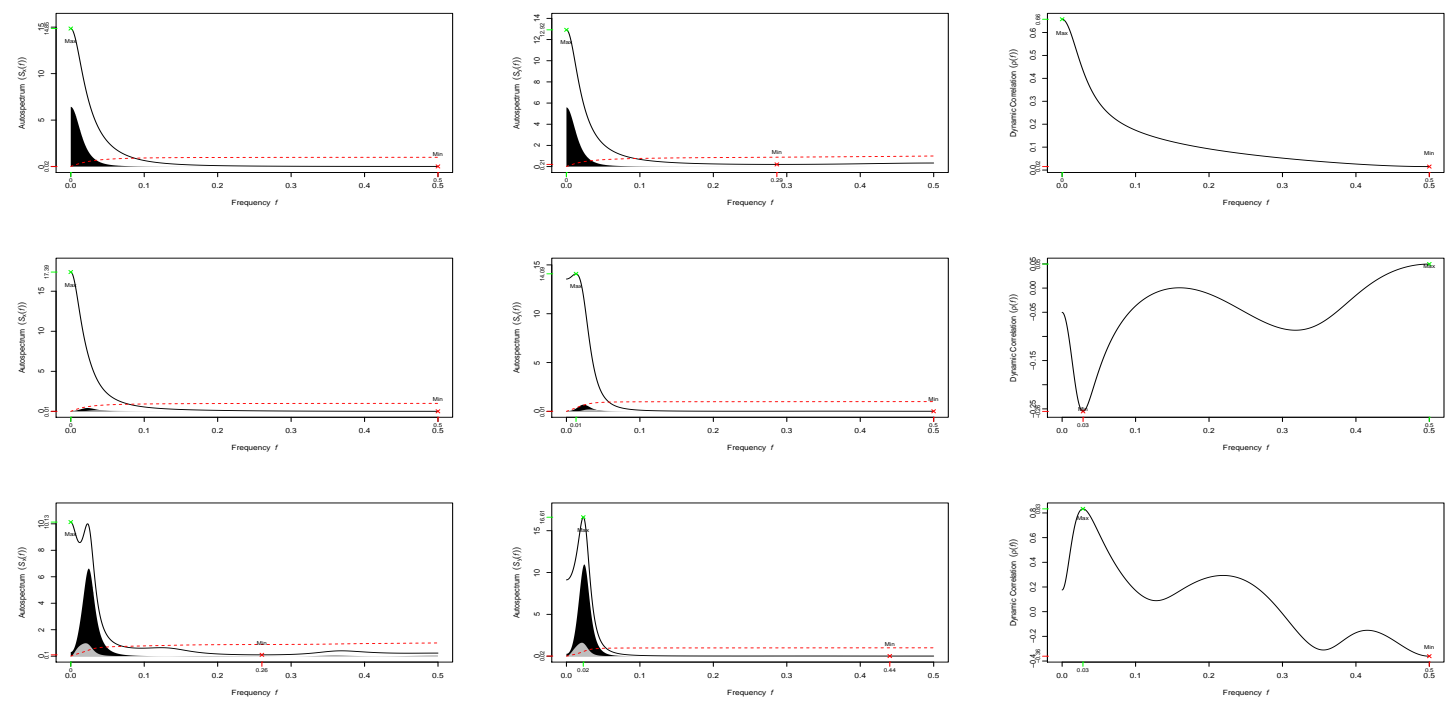

Figure 1. Bivariate spectral properties: EXR, EXP, BC; filter: HP

Note: First row - EXR vs. EXP, second row - EXR vs. BC, third row - EXP vs. BC

The first row of Figure 1 shows the autospectra of the real EUR/USD exchange rate and exports as well as the dynamic correlation between the series. Looking at the series' autospectra, we see that quite a significant part of the exports' variance is explained by exchange rate dynamics and vice versa. ${ }^{9}$ Furthermore, the two series are highly and positively correlated at the most relevant frequencies $\left(\rho_{\max }=0.66\right) .{ }^{10}$

\footnotetext{
${ }^{9}$ The explained variance is given by the colored area (black shaded area - "in-phase" component, grey shaded area - "out-of-phase" component of explained variance); see Appendix A.3 for details.

10 "Relevant" in the sense of these frequencies covering most of the series' variance.
} 
Things look somewhat different in case of the intra-series dynamics between the exchange rate and the business climate (second row of graphs). It can be seen that only a negligible part of the business climate's variance can be explained by the EUR/USD exchange rate. Additionally, the absolute value of the dynamic correlation at the relevant frequencies is much smaller. Looking at the last row of Figure 1 we see that there is a strong relationship between exports and the business climate in terms of explained variance and profound dynamic correlation. The latter takes on a maximum value of $\rho=0.83$ around the dominating low frequencies. Though less pronounced, the results for using the $\log \mathrm{D}$-filter are, in general, qualitatively in line with this picture. Detailed results are available on request from the authors.

\subsection{VAR model: Estimation and model checking}

This section describes our selection and estimation of a VAR $[\mathrm{p}]$-model in reduced form

$$
\boldsymbol{y}_{t}=\boldsymbol{c}+\boldsymbol{B}_{1} \boldsymbol{y}_{t-1}+\ldots+\boldsymbol{B}_{p} \boldsymbol{y}_{t-p}+\boldsymbol{u}_{t} \quad t=1, \ldots, T
$$

where $\boldsymbol{y}_{t}=\left[y_{1 t}, \ldots, y_{k t}\right]^{\prime}$ denotes a $k \times 1$ vector containing observed series (EXR,EXP,BC; i.e $k=3), \boldsymbol{B}_{i}, i=1, \ldots, p$, are (fixed) $k \times k$ coefficient matrices, $\boldsymbol{c}=\left[c_{1}, \ldots, c_{k}\right]^{\prime}$ denotes a (fixed) $k \times 1$ vector of intercept terms and $\boldsymbol{u}_{\boldsymbol{t}}=\left[u_{1 t}, \ldots, u_{k t}\right]^{\prime}$ a $k$-dimensional white noise process with $E\left[\boldsymbol{u}_{\boldsymbol{t}}\right]=\mathbf{0}, E\left[\boldsymbol{u}_{\boldsymbol{t}} \boldsymbol{u}_{\boldsymbol{t}}^{\prime}\right]=\boldsymbol{\Omega}_{u}$ and $E\left[\boldsymbol{u}_{\boldsymbol{s}} \boldsymbol{u}_{\boldsymbol{t}}^{\prime}\right]=\mathbf{0}$ for $s \neq t$.

The model order is set to $p=3$. It is chosen on the base of the AIC and FPE information criterion $\left(p_{\max }=24\right)$. Although, both criteria, the AIC as well as the FPE, overestimate the true order with positive probability (Lütkepohl 2006, p. 150), this choice seems to be unproblematic regarding degrees of freedom as well as estimation precision. ${ }^{11}$

Stacking right hand side terms, we get

$$
\boldsymbol{y}_{t}=\boldsymbol{X}_{t}^{\prime} \boldsymbol{B}+\boldsymbol{u}_{t} \quad t=1, \ldots, T
$$

where $\boldsymbol{B}=\operatorname{vec}\left(\boldsymbol{B}_{1}, \ldots, \boldsymbol{B}_{p}\right)$ and $\boldsymbol{X}_{t}^{\prime}=\boldsymbol{I}_{k} \otimes\left[1, \boldsymbol{y}_{t-1}^{\prime}, \boldsymbol{y}_{t-2}^{\prime}, \ldots, \boldsymbol{y}_{t-p}^{\prime}\right]$. We proceed with estimating the VAR[3]-model resorting to standard OLS. Results are shown in Table 3 and 4 of Appendix A.6. There is a number of insignificant coefficients. Following the

\footnotetext{
${ }^{11}$ The negative effect of $p$ being asymptotically too high can be corrected by estimating a subset VAR.
} 
principle of parsimony, we make parameter restrictions setting all insignificant parameters equal to zero. Estimating a subset VAR seems justified for two reasons. First, we know that $p$ selected on the base of AIC and FPE is too large with positive probability implying, at least, the elimination of some lags. Secondly, putting zero constraints on insignificant parameters will improve the model's forecast precision which has a positive impact on the results of impulse response (IR) analysis and forecast error variance decomposition (FEVD) as both rely on estimated "quantities" (Lütkepohl 2006, p. 207; Lütkepohl and Krätzig 2004, p. 180). Estimates for the subset VAR are shown in Table 5 of Appendix A.6. Lagged values of EXR have a significant positive impact on EXP as well as BC. Obviously, this stands in contrast to the exchange rate being best explained exclusively by its own past values. For all of the three single equations we observe satisfactory high values for adjusted R-squares and F-test statistics.

The subset VAR[3]-model is stable if all eigenvalues of $\mathbf{B}$ have moduli smaller than one, i.e., $\operatorname{det}(\mathbf{I}-\mathbf{B} z) \neq 0$ for $|z| \leq 1$. This is equivalent to saying that the characteristic polynomial $\mathbf{B}(z)=\operatorname{det}\left(\mathbf{I}-\mathbf{B}_{1} z-\ldots-\mathbf{B}_{p} z^{p}\right)$ of the VAR-filter $\mathbf{B}(L)$ has no roots in and on the complex unit root circle (Lütkepohl 2006). For our model, all eigenvalues of moduli of $\mathbf{B}$ are smaller than one $(0.902,0.857,0.857,0.404,0.404,0.390,0.385,0.271,0.000)$. Formal tests for residual autocorrelation do not give rise to concerns. The multivariate Portmanteau test finds that the null $\Gamma_{\widehat{\mathbf{u}}}(\tau)=0$ cannot be rejected at a $5 \%$-level ( $p$-value $=0.077),{ }^{12}$ i.e. $\widehat{\boldsymbol{u}}_{t}$ can be viewed as typical realizations of an uncorrelated process $\left\{\boldsymbol{u}_{t}\right\}$. This finding can be supported by a Breusch-Godfrey test that fits a VMA process

$$
\widehat{\boldsymbol{u}}_{t}=\boldsymbol{B}_{1} \widehat{\boldsymbol{u}}_{t-1}+\ldots+\boldsymbol{B}_{q} \widehat{\boldsymbol{u}}_{t-q}+\boldsymbol{\eta}_{t}
$$

where $\boldsymbol{\eta}_{t} \sim W N(\mathbf{0}, \boldsymbol{\Sigma})$. Following Lütkepohl and Krätzig (2004, p. 127) the number of lags for the Breusch-Godfrey statistics is smaller and equals 12 ( $p$-value $=0.0680$ ). Performing a mutlivariate Jarque-Bera test comes to the conclusion that the residuals are non-normally distributed. More precisely, only for the residuals of the exchange rate equation the normal distribution cannot be rejected ( $p$-value $=0.2228$ ). As a consequence, forecasting intervals may not be reliable (Lütkepohl 2006, p. 174). However, in sum, we may conclude that the subset $\operatorname{VAR}[3]$ is an adequate approximation of the underlying data generating process. In line with our theoretical considerations we find a positive (negative) effect of a Euro depreciation (appreciation) on exports and business

\footnotetext{
${ }^{12}$ Lags used for the Portmanteau statistic $=30$.
} 
climate.

\subsection{Identification and structural interpretation}

In the following, we focus on the causal interpretation of the dynamics incorporated in the VAR-model. As we have seen above our subset VAR[3]-model is stable, guaranteeing

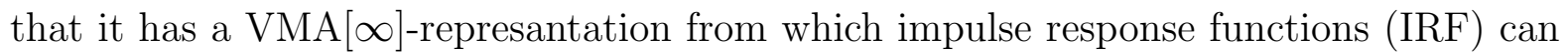
be calculated.

In disentangling the reduced form errors $\boldsymbol{u}_{t}$, which are correlated by definition, we -at first- rely on a Cholesky decomposition of the variance-covariance matrix $\boldsymbol{\Sigma}_{u}$. Orthogonalized shocks are given by $\boldsymbol{\epsilon}_{t}=C^{-1} \boldsymbol{u}_{t}$, where $C$ is lower-triangular such that $C C^{\prime}=\boldsymbol{\Sigma}_{u}{ }^{13}$ Together with our ordering of variables in $\boldsymbol{y}_{t}=\left[E X R_{t}, E X P_{t}, B C_{t}\right]^{\prime}$ this decomposition constitutes a Wold causal chain running from the exchange rate over exports to the business climate.

Note, this set-up implicitly assumes the dynamics of the EUR/USD exchange rate to be exogenously determined. This assumption seems justified as the EUR/USD exchange rate equals the relative price of the domestic currency. This price, however, is determined by the amount of Euros supplied by the ECB which can be assumed to act independently of German sectoral exports and/or confidence. Clostermann and Schnatz (2000) identify factors that determine the real EUR/USD exchange rate. According to their study, there is no need to assume that the exchange rate should be instantaneously influenced by German car and/or machinery exports to the US or by the business climate in the respective industries. ${ }^{14}$ Our assumption can also be supported in a more technical way by testing for Granger-causality. The hypothesis of "No instantaneous causality between: EXR and EXP, BC" can not be rejected at a $5 \%$ level of significance ( $p$-value $=0.2151)$.

German exports on the other hand are assumed to be contemporaneously influenced

\footnotetext{
${ }^{13}$ Though model residuals are merely correlated, orthogonalized shocks make sense as they render impulse responses comparable. However, in case IRFs (or the FEVD) are based on orthogonalized shocks results might be sensitive with regard to the ordering of variables. In our example this objection can, at least partly, be rejected by referring to the merely present instantaneous residual correlation (Lütkepohl and Krätzig 2004, p. 181). For further information on the robustness of results with regard to different variable orderings see Section 3.5.

${ }^{14}$ Of course, German exporst might influence the EUR/USD exchange rate via a change in domestic national income. However, the necessary adjustment processes will take some time.
} 
by the exchange rate. The assumption that the exchange rate in $t$ impacts on exports in $t$ does not seem to be problematic. There are several (empirical) studies that justify our belief in such a contemporaneous relation (e.g. De Grauwe and Verfaille 1988, Asseery and Peel 1991, Sauer and Bohara 2001). It is also natural to presume (as we do through our ordering) that sectoral export volumes are not contemporaneously influenced by sectoral confidence indicators, while the industries' business climate might be contemporaneously influenced by sectoral export activity.

Finally, our specification assumes that the business climate is instantaneously influenced by the exchange rate and exports but not vice versa. This is a plausible assumption with regard to the construction of the used indicators. As mentioned earlier, the business climate index published by the ifo institute is calculated as the mean of balances of percentage shares of positive and negative judgements reported by companies with regard to their current business situation and business expectations for the following six months. The current business situation and business expectations are measured on a 3-level-Likert scale representing a state $s \in S=\{+,=,-\}$. We may think of a variable on such a scale as resulting from an unobserved process $f(t)$. This idea can be formalized as follows: $s_{i, t}^{*}=f(t)+\nu_{t}$ with $\nu_{t} \sim N\left(0, \sigma^{2}\right), i=1, \ldots, n$ and $t=1, \ldots, T$. However, as survey participant $i$ must answer on the categorial scale we only observe

$$
s_{i, t}=\left\{\begin{array}{l}
+ \text { for } s_{i, t}^{*}>\tau^{+} \\
=\text {for } \tau^{+} \geq s_{i, t}^{*}>\tau^{-} \\
- \text {for } \tau^{-} \geq s_{i, t}^{*}
\end{array}\right.
$$

While the exact shape of $f(t)$ might be undefined, it is usually assumed that the unobserved process represents the business cycle (Seiler 2012). Yet, it seems not unrealistic to assume that $f(t)$ by anticipation of the survey participants also captures to some extent assessments of exchange rate dynamics and/or the development of exports to trading partners.

Due to these considerations we are confident that the Cholesky decomposition along with the chosen ordering of variables in $\boldsymbol{y}_{t}$ supplies us with structural exchange rate shocks that may be used for causal interpretation in a depreciation scenario.

Our strategy is to focus on the response of exports and business climate to orthogonalized shocks from the exchange rate. Corresponding IRFs are plotted in Figures 2 to 5. 
Overall, it seems that exports as well as the business climate react positively to a shock in the exchange rate. Exports show a rather instantaneous and significantly positive response in the short run. After about thirteen periods exports are back to normal, i.e. the bootstrapped confidence intervals ${ }^{15}$ cover the zero line again. Conclusions are quite different regarding the reaction of the business climate. First of all, BC seems to react in a less clear-cut way to a shock in the exchange rate. Secondly, the response is delayed for about two periods. Thirdly and most importantly, the confidence intervals clearly include the zero line allowing us not to speak of a significantly positive response of the business climate. In other words, exchange rate changes can leave the business climate unchanged.

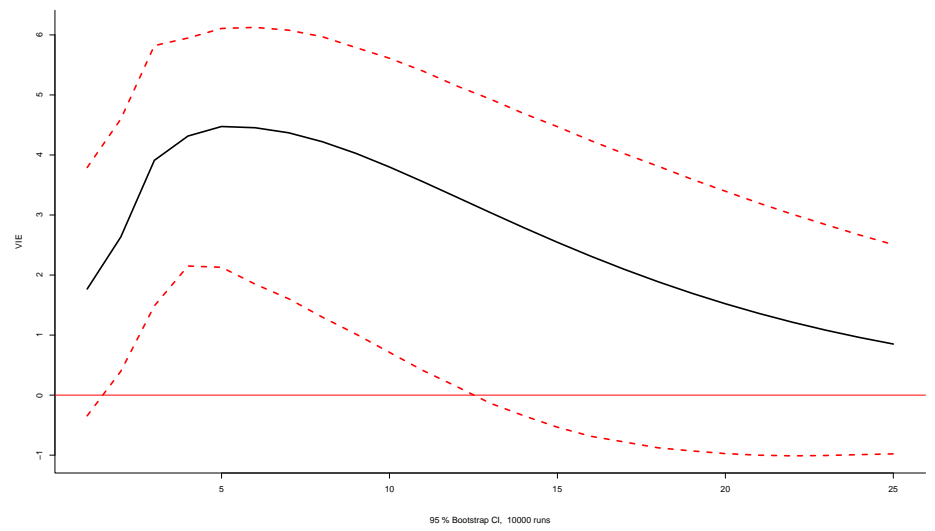

Figure 2. Response of EXP to EXR shock: Germany

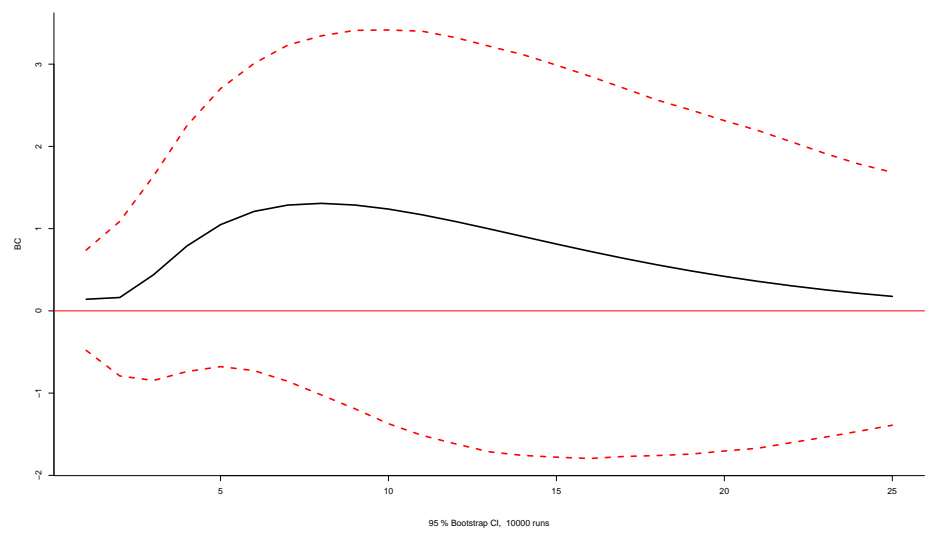

Figure 3. Response of BC to EXR shock: Germany

Figure 4 and Figure 5 also show the cumulated IRFs of EXP and BC which basically ${ }^{15} 95 \%$ confidence intervals were bootstraped with 10,000 runs. 
confirm our results. However, in a system of fully flexible exchange rates (free float), as in the case of the EUR/USD exchange rate, it would not be reasonable to assume constant shocks, i.e. an ongoing depreciation or appreciation of the Euro. ${ }^{16}$

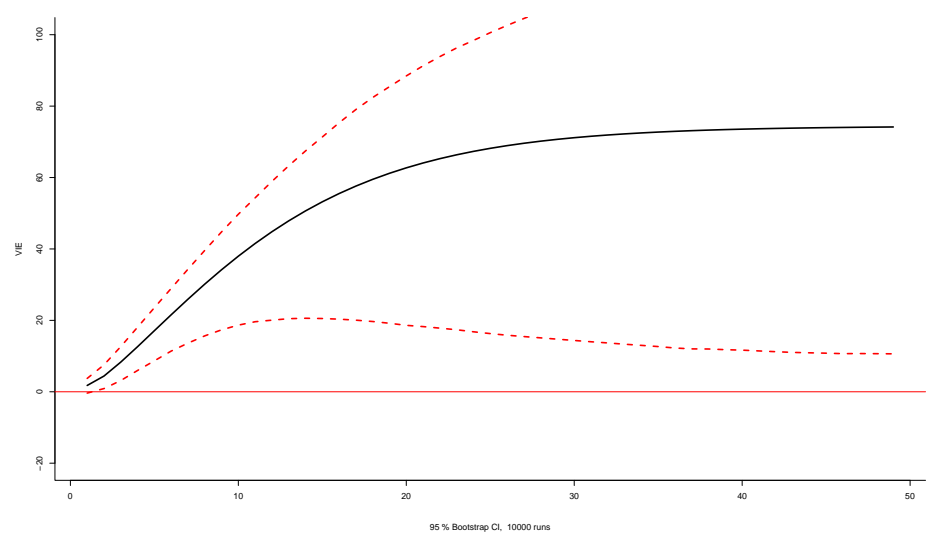

Figure 4. Response of EXP to cummulative EXR shock: Germany

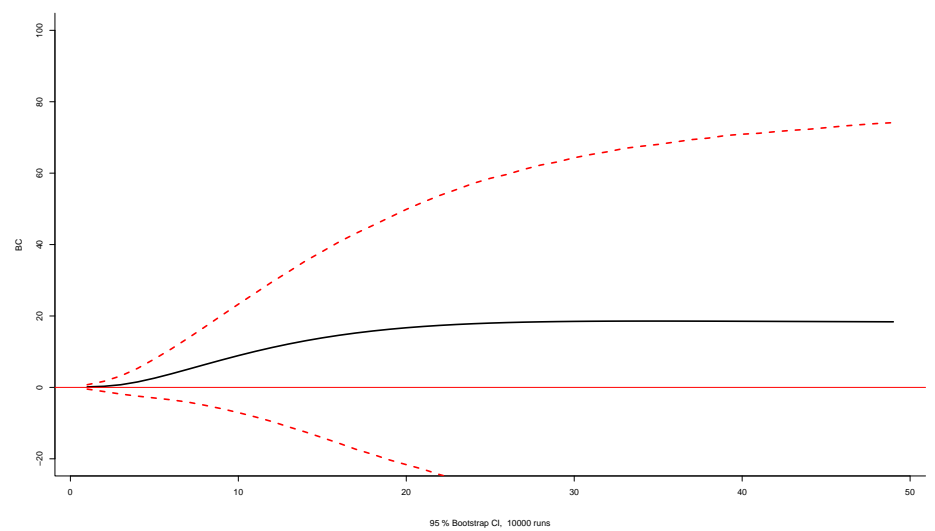

Figure 5. Response of BC to cummulative EXR shock: Germany

In a next and final step of our reference case, it is straight forward to look at the FEVD for the three variables. The forecast horizon is 12 months. Again by the variables ordering in the left hand side vector $\boldsymbol{y}_{\boldsymbol{t}}$ the following causal structur is assumed: exchange rate $\rightarrow$ exports $\rightarrow$ business climate. Not surprisingly for the subset VAR [3] the error variance of the exchange rate's $h$-step forecast is exclusively explained by own innovations. This result does not fundamentally change, if one looks at the unrestricted $\operatorname{VAR}[3]$ : The maximum contribution of EXP (BC) to forecast error variance is 6.0\% (3.8\%). Looking

\footnotetext{
${ }^{16}$ Nevertheless, it might be possible for fixed exchange rate regimes. A constant shock would correspond to a revaluation of the domestic currency.
} 
at the FEVD of exports, we see that innovations in the exchange rate gain significant impact on the variable's dynamics. For $h=12$ shocks of the exchange rate make up $30.9 \%$ of exports forecast error variance. Also the business climate has a strong effect on the dynamics of the EXP series (up to $28.5 \%$ for $h=12$ ). Finally and surprisingly, we observe that the exchange rate makes little to no contribution to the dynamics of the business climate. At maximum 3.6\% of the business climate's forecast error variance can be explained by innovations in the exchange rate. Of course, the exports' impact is somewhat stronger (amounting to up to 13.1\%). Dynamics of the business climate indicator are best explained by own innovations. Results are summarized in Figure 6 .
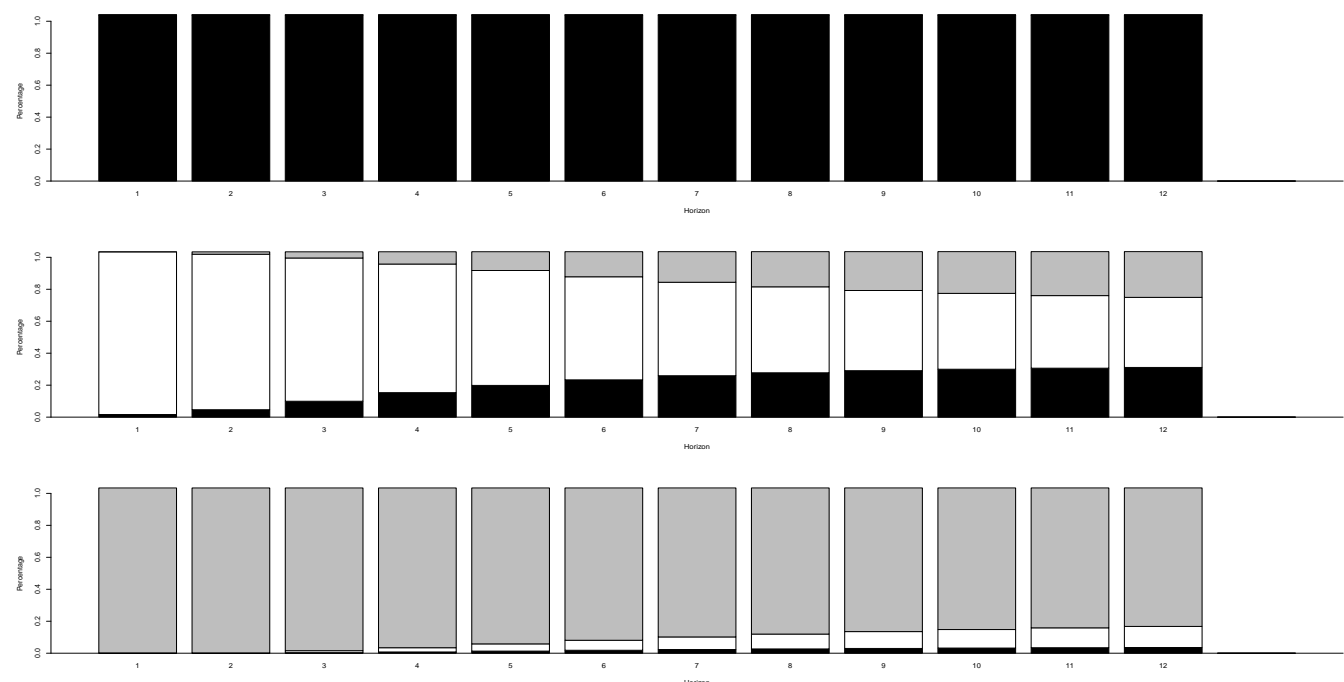

Figure 6. Forecast error variance decomposition (FEVD): Germany Note: black shaded: EXR, white shaded: EXP, grey shaded: BC FEVD from first to third row for EXR, EXP, BC

\subsection{Robustness of results}

To ensure that our results are not artificially generated by the respective filtering method or climate indicator we consider both $\log \mathrm{D}$-filtered series and alternative $\mathrm{BC}$ indicators. Figures given in Appendix A.5 show the IRFs and FEVD for different filtering methods ( $\mathrm{HP}$ and $\log \mathrm{D})$ and additional climate indicators for the respective industries (i.e. the Confidence Indicator and the Assessment of Export Order-Book Indicator published by the European Commission). Our results are robust with regard to different filtering methods. In particular the application of the $\log \mathrm{D}$ filter does not qualitatively change our main finding of a significant reaction of exports and an insignificant reaction of 
the business climate to an exchange rate shock. Results for the $\log \mathrm{D}$-filtered series are shown in Appendix A.5. The use of alternative climate indicators (i.e. the Confidence Indicator and the Assessment of Export Order-Book Indicator published by the European Commission) neither alters our results in a qualitatively relevant way (see Appendix A.5).

There might remain some objections regarding the use of the ifo business climate index as proxy for "pain" anticipated by firms against the backdrop of a strengthening Euro. One could argue that exports play only a minor role with regard to firms' profits compared to domestic sales. If this holds true, an omission bias is a probable caveat. In this case the insignificant reaction of the climate indicator to an exchange rate shock would neither be unexpected nor would it be an indication for hedging strategies or the like. However, there are two arguments speaking against such objections: First, in our baseline analysis we focus on the German automobile and mechanical engineering industries. For our period of observation, cars and machines clearly represent Germany's most important export goods. Hence, exports most reasonably play a major role for these industries. Secondly, our results are robust with regard to the use of the Assessment of Export Order-Book Indicator. This ensures that only firms are surveyed that actually engage in exporting and that judge their profit situation against the backdrop of export activity. Interestingly, a positive shock to the exchange rate does also not imply a significant impact on the firms' assessment of their export order-book levels. This might be seen as a further indication that transitory exchange rate shocks (due to some contractual arrangements or other sorts of hedging) are not internalized by long-run order levels.

Although the ordering of variables in $\boldsymbol{y}_{t}$ is reasonable, we also follow the suggestion by Sims (1981) and try various triangular orthogonalizations. It can be shown that our main result of a significant reaction of exports and an insignificant reaction of the respective climate indicator to an exchange rate shock is not altered by different variable orderings.

Notice that all our results do not change qualitatively if we shorten our sample, i.e. either focus on the post-1998 period or leave out the 2008/09 financial crisis.

Finally, we also checked the robustness of our results with regard to the use of tradewheighted exchange rates instead of bilateral exchange rates, i.e. we used the real effective exchange rate (CPI deflated, Euro area-17 countries vis-à-vis the EER-12 group of trading partners: AU, CA, DK, HK, JP, NO, SG, KR, SE, CH, GB and US), which is supplied by the Deutsche Bundesbank. Again, this leaves our results qualitatively unchanged. Detailed findings are available on request from the authors. 


\section{France and the United Kingdom}

It could be shown that our main finding is robust with regard to a wide range of different model specifications. However, do these results apply to other countries' core sectors? In order to answer this question, we conduct the analogue analysis using data for France and the United Kingdom. ${ }^{17}$ Results are summarized in Figures 6 to 13 of Appendix A.5. In the case of France, findings from the IR analysis look similar to the German case. However, they are less robust with regard to filtering. In case of the logD-filtered series, shocking the exchange rate seems to have a significantly negative influence on the respective climate indicator. This mixed finding carries over to the results of the FEVD. While in case of the HP-filtered series the exchange rate has no significant impact on the climate indicators' dynamics, for the log first differenced series we observe that in case of the Conifidence Indicator (Assessment of Export Order-Book Indicator) at maximum $11.7 \%(8.6 \%)$ of the forecast error variance is explained by exchange rate innovations. Compared to the German case this represents quite a share. Results are less ambiguous in case of relying on UK series. From the IRFs there is robust evidence that a positive shock to the GBP/USD exchange rate, i.e. a depreciation of the British Pound against the Dollar, has a comparatively strong and significantly negative effect on both climate indicators. In line with this finding, exchange rate innovations explain quite a substantial part of the indicators' forecast error variance, i.e. up to $16.3 \%(21.8 \%)$ in case of the (logD-filtered) Confidence Indicator (Assessment of Export Order-Book Indicator). This clearly higher immunity against exchange rate changes of the German and French as opposed to the UK automobile and mechanical engineering industries can be seen as an indirect benefit of the currency union and the common market. In this sense and against the backdrop of the Optimum Currency Area (OCA) approach, ultimately representing a cost-benefit approach, the cushioning currency union effect that in the end lets exchange rate changes not undermine the general business outlook in the core sectors can be seen as being part of the "uncommon arguments for common currencies" (Mundell 1973).

\footnotetext{
${ }^{17}$ As climate indicator for the respective industries the European Commission's Confidence and Assessment of Export Order-Book Indicator were used again.
} 


\section{The Role of the Currency Union}

As discussed in Section 2, there are several reasons for why the exchange rate's effect on exports and, in particular, on the business climate needs not to be unambiguous. Among them most prominent candidates are strategic firm behavior (PTM), low price elasticity of exports, relief on the cost side, natural hedging, or the growing importance of intra-European trade. A priori it is not clear which of these channels underlies our results. However, the similarity of results between industries in Germany and France is suggestive for the currency union to have played a role.

If the common market or currency union hypothesis holds, the effect of an exchange rate shock on the business climate in the exporting industries should have changed over time. As trade with other currency union members gained in weight (as compared to trade with the U.S.) the effect of a Euro depreciation or appreciation on the business climate might have decreased over time. Accordingly, an extraordinarily strong DM (or ECU) implied a strain on the business outlook of German exporters that was more severe before the Eurozone than nowadays. This is due to the fact that today foregone sales to the US (due to a strong Euro) can be more easily offset by trade with other Eurozone countries. However, this needs not to be the case for countries that are not members of the currency union.

In order to model indicator responses to an exchange rate shock over time we fit a T[ime]V[arying]P[arameter]-VAR with stochastic volatility à la Primiceri (2005) to our data. Note, although such a model does not require stationary series and, hence, does not require filtering of our series, we proceed in analogy to the preceding sections 3 and 4. This strategy ensures comparablity of standard VAR and TVP-VAR based findings.

\subsection{TVP-VAR model: estimation and model checking}

We fit the following model to the data:

$$
\boldsymbol{y}_{t}=\boldsymbol{c}_{t}+\boldsymbol{B}_{1, t} \boldsymbol{y}_{t-1}+\ldots+\boldsymbol{B}_{p, t} \boldsymbol{y}_{t-p}+\boldsymbol{u}_{t} \quad t=1, \ldots, T
$$

where $\boldsymbol{y}_{t}$ is an $n \times 1$ vector containing the (logD) exchange rate, exports, and the business

climate, respectively, $\boldsymbol{c}_{t}$ is an $n \times 1$ vector of time-varying intercepts, $\boldsymbol{B}_{i, t}, i=1, \ldots, p$ are $n \times n$ matrices of time-varying coefficients and $\boldsymbol{u}_{t}$ heteroskedastic unobservable shocks, 
where $\boldsymbol{u}_{t} \sim N\left(0, \boldsymbol{\Omega}_{t}\right)$. As the model is trivariate, $n=3$. In terms of $\boldsymbol{\Omega}_{t}$ we can think of the following triangular reduction

$$
A_{t} \Omega_{t} A_{t}^{\prime}=\Sigma_{t} \Sigma_{t}^{\prime}
$$

with $\boldsymbol{A}_{t}$ denoting the following lower triangular matrix

$$
\boldsymbol{A}_{t}=\left[\begin{array}{ccc}
1 & 0 & 0 \\
\alpha_{21, t} & 1 & 0 \\
\alpha_{31, t} & \alpha_{32, t} & 1
\end{array}\right]
$$

and $\Sigma_{t}$ being the diagonal matrix

$$
\boldsymbol{\Sigma}_{t}=\left[\begin{array}{ccc}
\sigma_{1, t} & 0 & 0 \\
0 & \sigma_{2, t} & 0 \\
0 & 0 & \sigma_{3, t}
\end{array}\right]
$$

From this we obtain

$$
\boldsymbol{y}_{t}=\boldsymbol{c}_{t}+\boldsymbol{B}_{1, t} \boldsymbol{y}_{t-1}+\ldots+\boldsymbol{B}_{p, t} \boldsymbol{y}_{t-p}+\boldsymbol{A}_{t}^{-1} \boldsymbol{\Sigma}_{t} \boldsymbol{\epsilon}_{t} \quad t=1, \ldots, T
$$

with $\boldsymbol{\epsilon}_{t} \sim N\left(0, \boldsymbol{I}_{n}\right)$. By $\boldsymbol{B}_{t}=\operatorname{vec}\left(\boldsymbol{B}_{1, t}, \boldsymbol{B}_{2, t}, \ldots, \boldsymbol{B}_{p, t}\right)$ equation (9) can be rewritten in the following way

$$
\boldsymbol{y}_{t}=\boldsymbol{X}_{t}^{\prime} \boldsymbol{B}_{t}+\boldsymbol{A}_{t}^{-1} \boldsymbol{\Sigma}_{t} \boldsymbol{\epsilon}_{t} \quad t=1, \ldots, T
$$

with

$$
\boldsymbol{X}_{t}^{\prime}=\boldsymbol{I}_{n} \otimes\left[1, \boldsymbol{y}_{t-1}^{\prime}, \boldsymbol{y}_{t-2}^{\prime}, \ldots, \boldsymbol{y}_{t-p}^{\prime}\right]
$$

where $\otimes$ denotes the Kronecker product. The model parameters evolve according to an $\mathrm{AR}(1)$ process

$$
\begin{aligned}
\boldsymbol{B}_{t} & =\boldsymbol{B}_{t-1}+\boldsymbol{\nu}_{t}, \quad \boldsymbol{\nu}_{t} \sim N(0, Q), \\
\boldsymbol{\alpha}_{t} & =\boldsymbol{\alpha}_{t-1}+\boldsymbol{\zeta}_{t}, \quad \boldsymbol{\zeta}_{t} \sim N(0, S), \\
\log \left(\boldsymbol{\sigma}_{t}\right) & =\log \left(\boldsymbol{\sigma}_{t-1}\right)+\boldsymbol{\eta}_{t}, \quad \boldsymbol{\eta}_{t} \sim N(0, W),
\end{aligned}
$$


with $\boldsymbol{\alpha}_{t}$ being the non-zero and non-one element of matrix $\boldsymbol{A}_{t}$ and $\boldsymbol{\sigma}_{t}$ being the vector of the diagonal elements of $\Sigma_{t} \cdot{ }^{18} S$ is assumed to be block-diagonal, i.e.

$$
S=\operatorname{Var}\left(\boldsymbol{\zeta}_{t}\right)=\left[\begin{array}{cc}
S_{1} & 0_{1 \times 2} \\
0_{2 \times 1} & S_{2}
\end{array}\right]
$$

where $S_{1}=\operatorname{Var}\left(\zeta_{21, t}\right)$ and $S_{2}=\operatorname{Var}\left(\left[\zeta_{31, t}, \zeta_{32, t}\right]^{\prime}\right)$, with $\operatorname{Var}(\cdot)$ denoting the variance operator.

Together, equations (10) to (13) form a state-space representation of the TVP-VAR. The model innovations are assumed to be jointly normal. Again the model order has been chosen to be $p=3$.

In estimating the model we follow a Bayesian approach rather than relying on Maximum Likelihood (ML) estimation. This is due to the fact that, given the high dimensionality and nonlinearity of the problem, ML-estimates are not efficient. ${ }^{19}$ Even when being able to compute an ML-estimate of which one can be sure that it is not just a local maximum, it remains unsettled how to deal with the uncertainty related to the estimate. Bayesian inference deals with this problem by evaluating the posterior distributions of states and parameters and thus incorporates the uncertainty about these quantities. We will use a Gibbs sampler, which is a special variant of Markov Chain Monte Carlo (MCMC) methods, to determine the posterior distributions of $\boldsymbol{B}^{T}, \boldsymbol{A}^{T}$, $\Sigma^{T}$, and the hyperparamteres $(Q, S, W) \cdot{ }^{20}$

We assume that the initial states for $\boldsymbol{B}^{T}, \boldsymbol{A}^{T}, \boldsymbol{\Sigma}^{T}$ and the hyperparamteres are independent of each other. Furthermore, it is assumed that the priors $p\left(\boldsymbol{B}_{0}\right), p\left(\boldsymbol{\alpha}_{0}\right)$ and $p\left(\log \left(\boldsymbol{\sigma}_{0}\right)\right)$ are normally distributed, whereas the priors for $Q, W$ and $S$ follow an independent inverse-Wishart distribution with scale matrix $\Psi$ and degrees of freedom $m$. Estimating a time-invariant VAR by OLS on a small training sample of 30 observations

\footnotetext{
${ }^{18}$ While $\boldsymbol{B}_{t}$ and $\boldsymbol{A}_{t}$ are modeled as random walks without drift the stochastic volatilities follow a geometric random walk. The random walk assumption for the coefficients and the contemporaneous relations comes along with a number of disadvantages; see Primiceri (2005) for a detailed discussion. However, it has the great advantage of reducing the number of parameters to be estimated.

${ }^{19}$ One particular drawback is that a complicated model as defined in the previous section will usually come along with a Likelihood function including multiple peaks; see Primiceri (2005) for a detailed discussion of problems related to ML-estimation of state space models.

${ }^{20}$ Superscript $(\cdot)^{T}$ indicates that all information up to point $T$ is used in the estimation of parameters of interest. This is because MCMC is a smoothing rather than a filtering method.
} 
is used to calibrate the priors. Letting $\hat{x}$ denote the point estimate of an unknown parameter $x$ and $\hat{V}_{\hat{x}}$ the respective variance, we get the following priors

$$
\begin{aligned}
\boldsymbol{B}_{0} & \sim N\left(\hat{\boldsymbol{B}}_{O L S}, 3 \cdot \hat{V}_{\hat{\boldsymbol{B}}_{O L S}}\right), \\
\boldsymbol{A}_{0} & \sim N\left(\hat{\boldsymbol{A}}_{O L S}, 3 \cdot \hat{V}_{\hat{\boldsymbol{A}}_{O L S}}\right), \\
\log \left(\boldsymbol{\sigma}_{0}\right) & \sim N\left(\log \left(\hat{\boldsymbol{\sigma}}_{O L S}\right), 3 \cdot \boldsymbol{I}_{3}\right), \\
Q & \sim I W\left(k_{Q}^{2} \cdot 30 \cdot \hat{V}_{\hat{\boldsymbol{B}}_{O L S}}, 30\right), \\
W & \sim I W\left(k_{W}^{2} \cdot 3 \cdot \boldsymbol{I}_{3}, 3\right), \\
S_{1} & \sim I W\left(k_{S}^{2} \cdot 2 \cdot \hat{V}_{\hat{\boldsymbol{A}}_{1, O L S}}, 2\right), \\
S_{2} & \sim I W\left(k_{S}^{2} \cdot 3 \cdot \hat{V}_{\hat{\boldsymbol{A}}_{2, O L S}}, 3\right),
\end{aligned}
$$

with $k_{Q}=0.01, k_{S}=0.1$ and $k_{W}=0.01$. For $(W, S)$ the degrees of freedom $m$ are set to one plus the dimension of the respective matrix. This is in any case the minimum number of degrees of freedom in order for the inverse-Wishart distribution to be properly specified (Primiceri 2005). In case of $(Q)$ the degrees of freedom $m$ are set to 30 , which is the size of the training sample and leads to a slightly tighter prior. Except for $W$, for all the priors on the hyperparameters the scale matrices are constant fractions of the variances resulting from the model fitted to the training sample. Chosen in that way the priors are not completely uninformative yet still rather diffuse. This guarantees that the information embodied in the priors is soon dominated by the information contained in the data.

Simulating the joint posterior distribution $\left(\boldsymbol{B}^{T}, \boldsymbol{A}^{T}, \boldsymbol{\Sigma}^{T}, Q, S, W\right)$ via Gibbs sampling takes place according to the following steps: Sequentially draw $\left(\boldsymbol{B}^{T}\right),\left(\boldsymbol{A}^{T}\right),\left(\boldsymbol{\Sigma}^{T}\right)$ and the hyperparameters $(Q, S, W)$ given the data and the rest of the parameters. ${ }^{21}$ We perform 30,000 sampling iterations, discarding the first 20,000 draws as burn-in phase. The Gibbs sampler, as every Markov chain sampler, is a dependence chain algorithm, i.e. the different draws are not independent from each other. In order to break the correlation between the different draws, we keep only every tenth draw. Additionally, following Cogley and Sargent (2001), all draws for the coefficient vector that would lead to an explosive solution of the model are discarded.

\footnotetext{
${ }^{21}$ See Appendix A.4 for a detailed description of the separate Gibbs sampling steps.
} 


\subsection{The business climate response over time}

Figures 7 to 9 display the absolute response of the sectoral business climate indicator to an exchange rate shock after six months $(6 \mathrm{M})$ by the respective solid line country by country. Additionally, the running mean, i.e. a mean that is calculated anew with each new observation, of this response over time is shown by a dotted line in each diagram. For the sake of comparability ordinate values are identically scaled. Obviously, the mediumterm business climate's reaction to an exchange rate shock developed rather differently for the different economies. This holds, in particular, in the aftermath of the final phase of convergence, that is the final exchange rates fixing and the transition to the Euro, in January 1999.

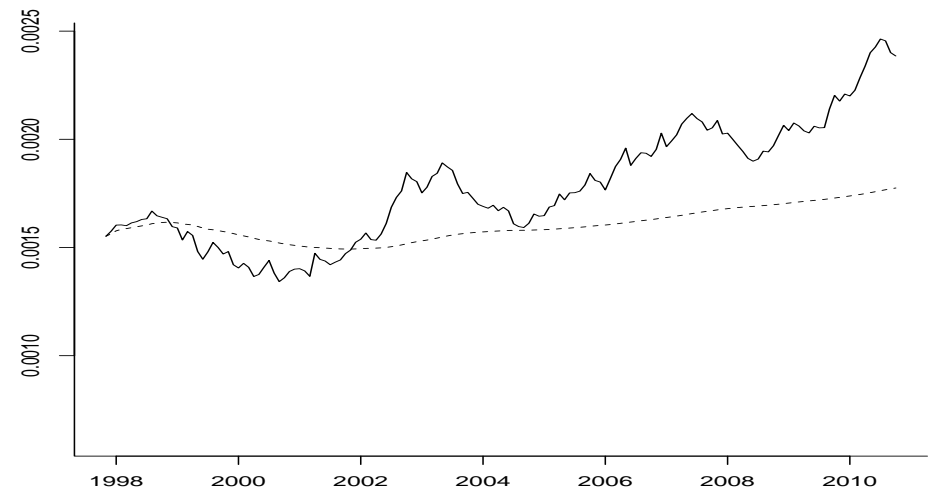

Figure 7. $6 \mathrm{M}$ response of $\mathrm{BC}$ to EXR shock: UK

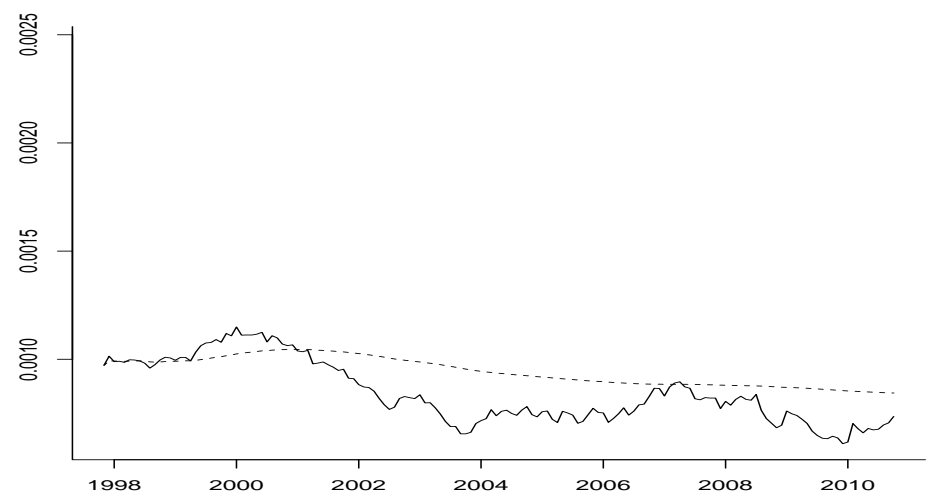

Figure 8. 6M response of BC to EXR shock: Germany 


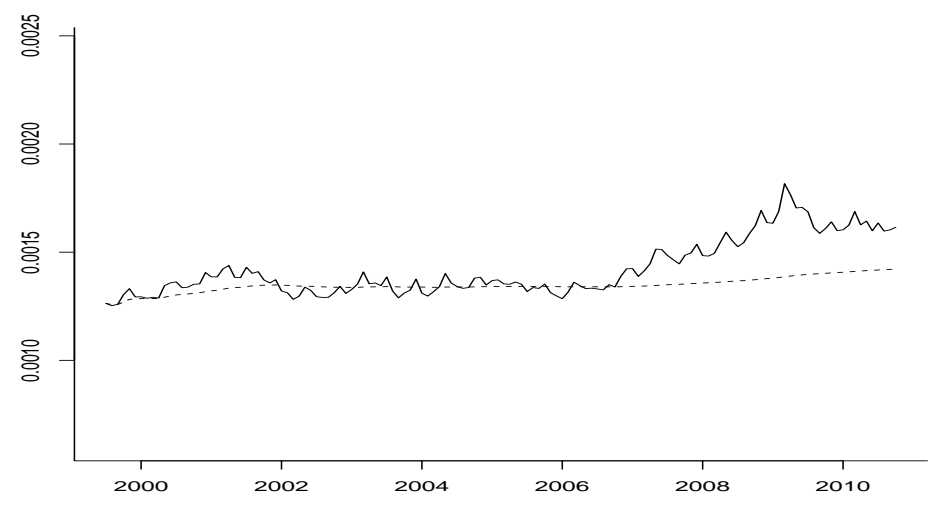

Figure 9. 6M response of BC to EXR shock: France

Responses conspicuously drift apart with the actual implementation of the single currency for the common market in January 2002. ${ }^{22}$ The starkest contrast is given comparing the time-varying response function of German core exporting sectors (Figure 8) with the corresponding one for the UK (Figure 7). Although Germany starts from a slightly lower level of medium run exchange rate susceptibility of its core sectors, it clearly falls over nearly the entire period of observation. The opposite applies in the case of the UK.

For French key exporting sectors the reaction of business confidence to exchange rate shocks has been rather stable over the total period of observation (Figure 9). The running mean (dotted line) is basically constant, suggesting no change in responsiveness over time apart from transient changes that are transitory in nature.

We cautiously interpret these findings as lending support to the common market and common currency explanation for the overall weak and, in the case of Germany, rather declining responsiveness of Eurozone members' business confidence to a EUR/USD exchange rate shock: As foregone sales to the US due to a strong Euro can be offset more efficiently by trade among members within the currency union, the importance of EUR/USD exchange rate shocks for the business climate decreased after the installation of the Eurozone.

\footnotetext{
${ }^{22}$ In case of France the response is plotted only from 1999 onwards as the training sample consists of 50 as opposed to 30 observations for the other countries.
} 


\section{Conclusion}

The paper started by presuming that looking at the reaction of exports due to exchange rate changes is not satisfactory when addressing the question whether an appreciation of the Euro causes automobile and mechanical engineering industries in the EU "pain." Estimating a trivariate VAR, we find a depreciation of the Euro to have a positive impact on exports and confidence indicators for German and French data. The effect is, however, insignificant in the case of the confidence indicators: Implied impulse responses show that shocks in the exchange rate lead to a significant reaction of exports, while there might be neither a reaction of the business climate nor of order book assessments or business confidence in general. Finally, FEVD analysis revealed that the exchange rate contributes little to nothing to the dynamics of confidence indicators. The latter does not apply to the UK if we proceed analogously with the GBP/USD exchange rate and the UK sectoral series. This relatively higher susceptibility of UK core industries can be interpreted as an indication for a rather indirect benefit of the currency union. Looking at the business climate's response to exchange rate shocks over time additionally supports this view. In contrast to the UK, the two Eurozone economies' business confidence responsiveness to exchange rate changes is weak and for Germany also on the decline since the transition to the Euro and the installation of the currency union. This represents a remarkable finding in times of large-scale bailouts, when positive externalities of the Euro are frequently praised in political justifications but seldomly challenged in empirical studies.

In the recent debate triggered by the efforts of the Bank of Japan to strategically lower real exchange rates, our results suggest that "competitive depreciation" is neither an option nor a threat for European currency union members' core industries. 


\section{References}

[1] Asseery, A. and D.A. Peel (1991). The effects of exchange rate volatility on exports: some new estimates. Economic Letters 37, 173-177.

[2] Belke, A., Goecke, M., and M. Guenther (2009). When Does it Hurt? The Exchange Rate "Pain Threshold" for German Exports. DIW Discussion Papers, No. 943.

[3] Bodnar, G.M. and W.M. Gentry (1993). Exchange rate exposure and industry characteristics: evidence from Canada, Japan, and the USA. Journal of International Money and Finance 12, 29-45.

[4] Carter, C.K. and R. Kohn (1994). On Gibbs sampling for state space models. Biometrika 81, 541-553.

[5] CESifo (2010). Industrie: Optimismus nimmt wieder zu. Konjunkturperspektiven $37,1-12$.

[6] Clostermann, J. and B. Schnatz (2000). The Determinants of the Euro-Dollar Exchange Rate-Synthetic Fundamentals and a Non-existing Currency. Economic Research Group of the Deutsche Bundesbank Discussion Papers, No. 2.

[7] Cogley, T. and T.J. Sargent (2001). Evolving Post-World War II US Inflation Dynamics. NBER Annual 2001.

[8] Croux, C., Forni, M., and L. Reichlin (2001). A measure of comovement for economic variables: theory and empirics. Review of Economics and Statistics 83, 232-241.

[9] De Grauwe, P. and G. Verfaille (1988). Exchange Rate Variability, Misalignment, and the European Monetary System. University of Chicago Press.

[10] Deutsche Bundesbank (2008). Macroeconomic Effects of Changes in Real Exchange Rates. Monthly Report 03/08, 33-46.

[11] Falk, M. and R. Falk (2000). Pricing to market of German exporters: evidence from panel data. Empirica 27, 21-46.

[12] Frankel, J. and A. Rose (2002). An Estimate of the Effect of Common Currencies on Trade and Income. Quarterly Journal of Economics 117, 437-466. 
[13] Fratzscher, M. (2008). Communication and exchange rate policy. Journal of Macroeconomics 30, 1651-1672.

[14] Greenaway, D., Kneller, R., and X. Zhang (2010). The effect of exchange rates on firm exports: the role of imported intermediate inputs. World Economy 33, 961-986.

[15] Griffin, J.M. and R.M. Stulz (2001), International competition and exchange rate shocks: a cross-country industry analysis of stock returns, Review of Financial Studies $14,215-241$.

[16] Kim, S., Shephard, N., and S. Chib (1998). Stochastic volatility: likelihood inference and comparison with ARCH models. The Review of Economic Studies 65, 361-393.

[17] Knetter, M. (1993). International comparisons of pricing-to-market behavior. American Economic Review 83, 473-486.

[18] Krugman, P. (1986). Pricing to market when the exchange rate changes. NBER Working Paper, No. 1926.

[19] Lütkepohl, H. (2005). New introduction to multiple time series analysis. Springer, Heidelberg.

[20] Lütkepohl, H. and M. Krätzig (2004). Applied time series econometrics. Cambridge University Press, Cambridge.

[21] Mundell, R.A. (1973). Uncommon arguments for common currencies, in H.G. Johnson and A.K. Swoboda (eds.). The Economics of Common Currencies. Allen \& Unwin, Sydney, 114-132.

[22] Primiceri, G.E. (2005). Time varying structural vector autoregressions and monetary policy. Review of Economic Studies 72, 821-852.

[23] Ravn, M.O. and H. Uhlig (2002). On adjusting the Hodrick-Prescott filter for the frequency of observations. Review of Economics and Statistics 84, 371-376.

[24] Sauer, C. and A.K. Bohara (2001). Exchange rate volatility and exports: regional differences between developing and industrialized countries. Review of International Economics 9, 133-152.

[25] Seiler, C. (2012). On the Robustness of the Balance Statistics with respect to Nonresponse. ifo Working Paper, No. 126. 
[26] Sims, C.A. (1981). An autoregressive index model for the U.S. 1948-1975, in J. Kmenta and J.B. Ramsey (eds.). Large-Scale Macro-Econometric Models. NorthHolland, Amsterdam, 283-327.

[27] Sinn, H.-W. and F. Westermann (2001). Why has the euro been falling? An investigation into the determinants of the exchange rate. NBER Working Paper, No. 8352.

[28] Tintner, G., Rao, J.N.K., and H. Strecker (1978). New results in the variate difference method. Vandenhoeck und Ruprecht, Göttingen.

[29] Williamson, R. (2001). Exchange rate exposure and competition: evidence from the automotive industry. Journal of Financial Economics 59, 441-475. 


\section{A Appendix}

\section{A.1 Stylized model of export reaction to exchange rates}

The most straightforward way to illustrate possible reactions of exports to exchange rate movements is to consider a most basic model economy, consisting of two countries and two goods that are homogeneous and traded on the world market. Let $E_{a}$ denote excess demand for good $a$, where excess demand is defined as $E_{a}=Q_{a}^{d}-Q_{a}^{s}$. Additionally, let an asterisk denote variables referring to the foreign economy. Hence, $E_{a}<0$ corresponds to an excess supply of $a$. In this stylized model, a world market equilibrium is given by

$$
-E_{a}\left(p_{a}\right)=E_{a}^{*}\left(p_{a}^{*}\right) \wedge E_{b}\left(p_{b}\right)=-E_{b}^{*}\left(p_{b}^{*}\right)
$$

abstracting from any substitution effects between the two goods, $a$ and $b$, that is, if we let excess demand and excess supply depend solely on the price of the respective good. Suppose that the domestic country is a net exporter of good $a$. In the following, we take the perspective of the domestic economoy and focus on its exports.

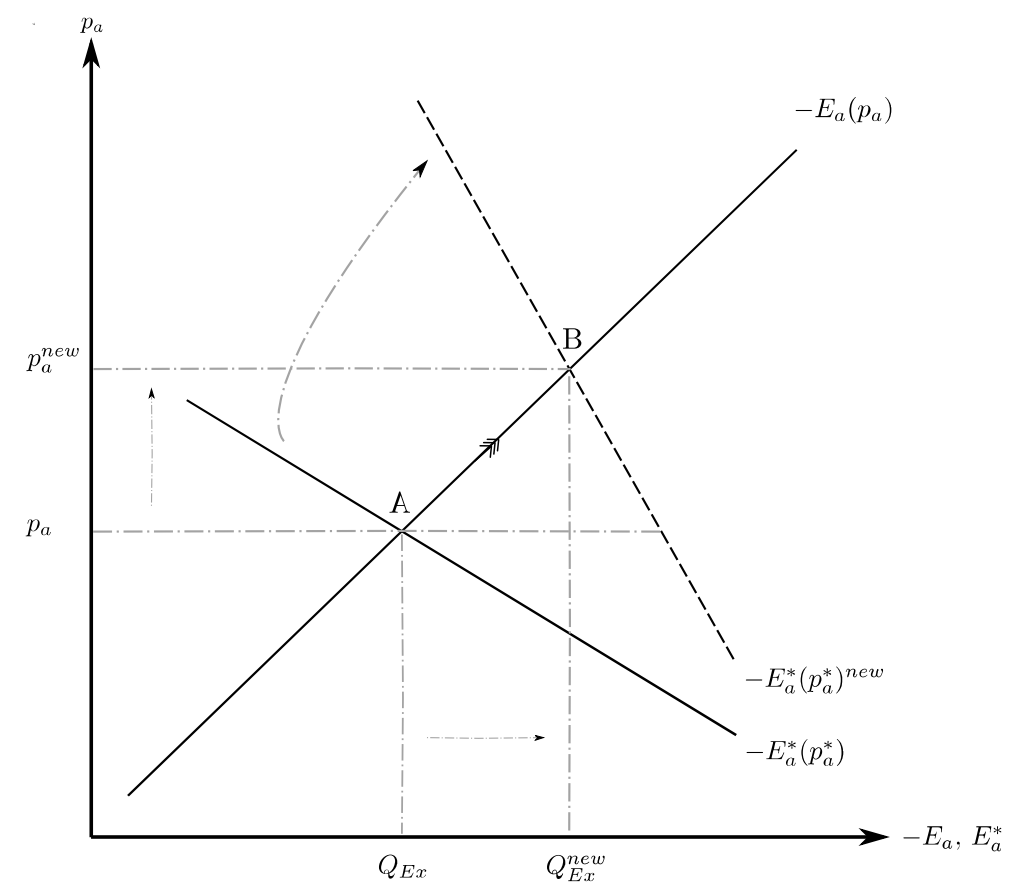

Change in export volume following a depreciation of domestic currency

Let the exchange rate be given in price notation and consider a depreciation of the domestic currency. We assume for simplicity reasons that exports are denoted in domestic 
currency. If the exchange rate depreciates, a given foreign price for good $a$ then translates into an increase in the "domestic" price. ${ }^{23}$ World market demand for good $a$ increases as domestic goods have become less expensive for foreigners. Assuming further the decision of supplying $a$ by domestic producers depends on the domestic price only, the supply of $a$ remains unchanged. This in turn induces an increase in excess demand for good $a$ on the world market. As a consequence, the price of $a$ in domestic currency gradually increases until a new equilibrium is reached (AB in Figure 1). In the new world market equilibrium a higher export quantity for an increased domestic price results, i.e. the export volume rises due to a depreciation of the domestic currency. The same reasoning though with different signs applies for an appreciation scenario.

\section{A.2 Data plots and descriptive statistics}
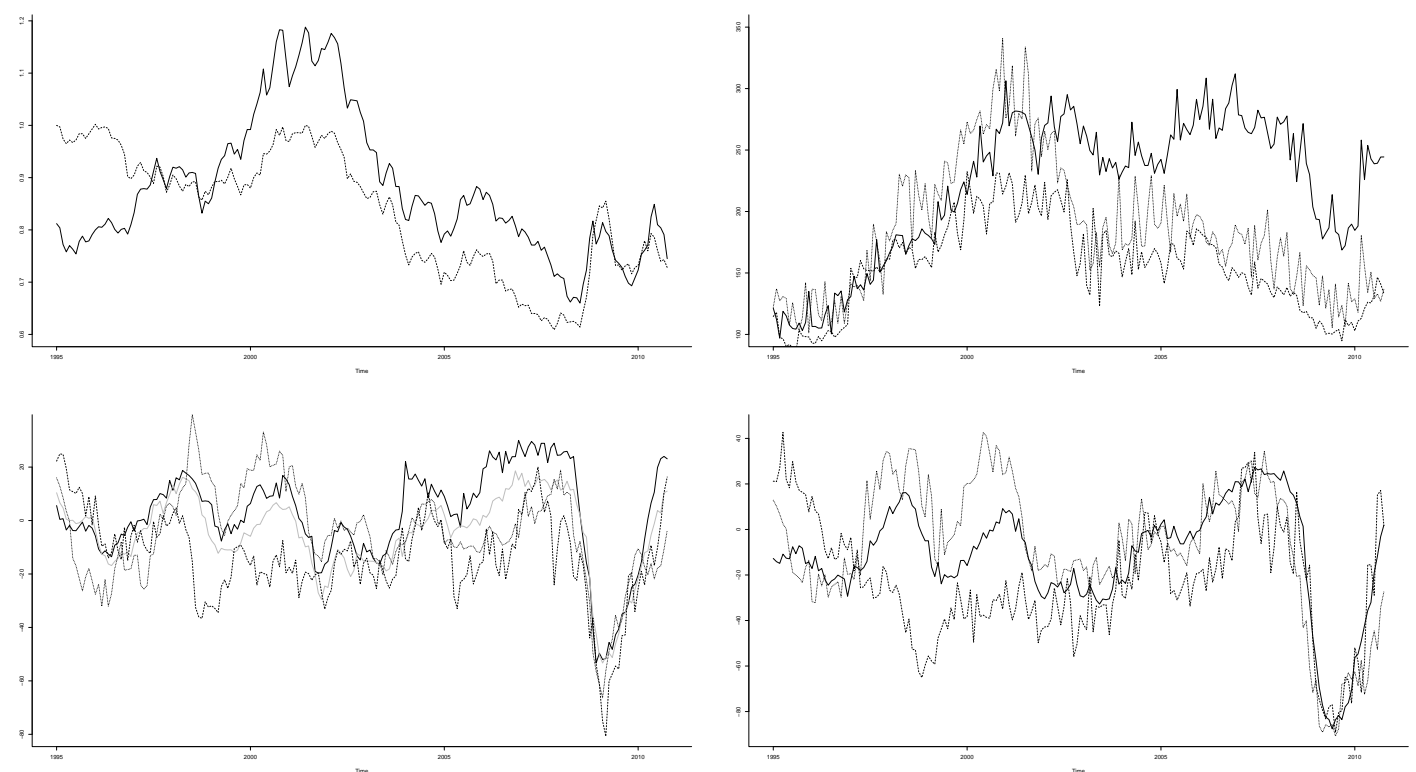

Figure 1: Clockwise from upper left corner: real EUR/USD exchange rate (solid) and real GBP/USD exchange rate (dashed), vehicle and machinery exports to U.S. for Germany (solid), UK (dashed) and France (dotted), Assessment of Export Order-Book Indicator in automobile and mechanical engineering industry for Germany (solid), UK (dashed) and France (dotted), ifo Business Climate (solid) as well as European Commission's Confidence Indicator in automobile and mechanical engineering industry for Germany (grey), UK (dashed) and France (dotted)

${ }^{23}$ For period $t=0: \frac{1 p_{a}}{1 p_{a} *} \Rightarrow 10 p_{a}=10 p_{a}^{*}=100 a$; for period $t=1: \frac{2 p_{a}}{1 p_{a}^{*}} \Rightarrow 20 p_{a}=10 p_{a}^{*}=100 a$. 


\begin{tabular}{lcccccccccccc}
\hline \hline Variable & \multicolumn{4}{c}{ Germany } & \multicolumn{4}{c}{ France } & \multicolumn{4}{c}{ UK } \\
& Min & Max & Mean & Sd & Min & Max & Mean & Sd & Min & Max & Mean & Sd \\
\hline EXR & 0.66 & 1.19 & 0.88 & 0.131 & 0.66 & 1.19 & 0.88 & 0.13 & - & - & - & - \\
EXR_GB & - & - & - & - & - & - & - & - & 0.61 & 1.00 & 0.83 & 0.12 \\
EXP & 96.97 & 312.02 & 219.80 & 57.25 & 101.16 & 341.04 & 185.59 & 53.37 & 85.45 & 232.54 & 154.99 & 37.72 \\
BC & -53.35 & 30.00 & 1.99 & 17.72 & - & - & - & - & - & - & - & - \\
COF & -53.30 & 18.60 & -4.89 & 14.90 & -66.30 & 39.65 & -4.79 & 17.88 & -80.70 & 24.95 & -13.62 & 17.01 \\
ASS_EXP & -87.60 & 27.25 & -12.02 & 24.20 & -90.75 & 42.60 & -7.61 & 29.83 & -89.15 & 42.65 & -23.59 & 26.11 \\
\hline
\end{tabular}

Table 1: Descriptive statistics for real EUR/USD exchange rate (EXR), real GBP/USD exchange rate (EXR_GB), value index of exports (EXP), ifo Business Climate (BC), European Commission's Confidence Indicator (COF) and European Commission's Assessment of Export Order-Book Indicator (ASS_EXP)

\section{A.3 Derivation of (multivariate) frequency analysis measures}

\section{A.3.1 Spectrum}

The spectrum of a stationary process $x_{t}$ is defined as the Fourier transform of the autocovariance function $\gamma_{x}(\tau), \tau=0, \pm 1, \pm 2, \ldots$

$$
f_{x}(\omega)=\frac{1}{2 \pi} \sum_{\tau=-\infty}^{\infty} \gamma_{x}(\tau) e^{-i \omega \tau}
$$

with $\omega \in[-\pi, \pi]$. The total area under the spectrum equals the process variance, i.e.

$$
\gamma_{x}(0)=\int_{-\pi}^{\pi} f_{x}(\omega) d \omega
$$

\section{A.3.2 Cross-Spectrum}

In case of two stationary time series $x_{t}$ and $y_{t} f_{x}(\omega)$ is the autospectrum of the $x_{t}$ and $f_{x y}(\omega)$ is the cross-soectrum for $x_{t}$ and $y_{t}$. Both are elements of the spectral density matrix, which is defined as the Fourier transform of the covariance matrix $\boldsymbol{\Gamma}_{x y}(\tau) . \tau=$ $0,1,2, \ldots$

$$
\boldsymbol{F}_{x y}(\omega)=\frac{1}{2 \pi} \sum_{\tau=-\infty}^{\infty} \boldsymbol{\Gamma}_{x y}(\tau) e^{-i \omega \tau}
$$


with $\omega \in[-\pi, \pi]$. The cross-spectrum at frequency $\omega$ is given by

$$
f_{x y}(\omega)=c_{x y}(\omega)-i q_{x y}(\omega),
$$

with $\omega \in[-\pi, \pi]$ and $c_{x y}(\omega)$ being the cospectrum and $q_{x y}(\omega)$ the quadrature spectrum.

\section{A.3.3 Explained Variance}

Using the squared coherency

$$
s c(\omega)=\frac{\left|f_{x y}(\omega)\right|^{2}}{f_{x}(\omega) f_{y}(\omega)},
$$

which is defined $0 \leq s c(\omega) \leq 1$, one can decompose the spectrum of $y_{t}$ into the fraction that can be explained by the filtered series $x_{t}$ and a residual spectrum. Regressing $y_{t}$ on $x_{t}$ leads to the following minimization problem

$$
\min \sigma^{2}=E[y_{t}-\underbrace{B(L) x_{t}}_{\hat{y}_{t}}]^{2} .
$$

The optimal filter is given by

$$
\hat{B}(\omega)=\frac{f_{x y}(\omega)}{f_{x}(\omega)},
$$

with $\omega \in[-\pi, \pi]$. Thus, one gets

$$
f_{y}(\omega)=f_{\hat{y}}(\omega)+f_{u}(\omega),
$$

with

$$
f_{\hat{y}}(\omega)=|\hat{B}(\omega)|^{2} f_{x}(\omega) .
$$

Hence, equation (8) can be rewritten as

$$
\begin{aligned}
f_{y}(\omega) & =|\hat{B}(\omega)|^{2} f_{x}(\omega)+f_{u}(\omega) \\
& =\frac{\left|f_{x y}(\omega)\right|^{2}}{f_{x}(\omega)}+f_{u}(\omega) \\
& =\frac{\left|f_{x y}(\omega)\right|^{2}}{f_{x}(\omega) f_{y}(\omega)} f_{y}(\omega)+f_{u}(\omega) \\
& =s c(\omega) f_{y}(\omega)+f_{u}(\omega) .
\end{aligned}
$$


Using equation (2) we get

$$
\underbrace{\int_{-\pi}^{\pi} f_{y}(\omega) d \omega}_{\gamma_{y}(0)}=\underbrace{\int_{-\pi}^{\pi} s c(\omega) f_{y}(\omega) d \omega}_{\text {explained variance }}+\underbrace{\int_{-\pi}^{\pi} f_{u}(\omega) d \omega}_{\hat{\sigma}^{2}} .
$$

Thus, the variance of $y_{t}$ is decomposed into an explained (explained by $x_{t}$ ) and an unexplained part frequency by frequency. By

$$
\begin{aligned}
s c(\omega) & =\frac{\left|f_{x y}(\omega)\right|^{2}}{f_{x}(\omega) f_{y}(\omega)} \\
& =\frac{c_{x y}(\omega)^{2}+q_{x y}(\omega)^{2}}{f_{x}(\omega) f_{y}(\omega)}
\end{aligned}
$$

this can further be decomposed into

$$
\begin{aligned}
& \underbrace{\int_{-\pi}^{\pi} f_{y}(\omega) d \omega}_{\gamma_{y}(0)}=\underbrace{\int_{-\pi}^{\pi} \frac{c_{x y}(\omega)^{2}}{f_{x}(\omega) f_{y}(\omega)} f_{y}(\omega) d \omega}_{\text {explained variance (in-phase) }}+\underbrace{\int_{-\pi}^{\pi} \frac{q_{x y}(\omega)^{2}}{f_{x}(\omega) f_{y}(\omega)} f_{y}(\omega) d \omega}_{\text {explained variance (out-of-phase) }} \\
& +\underbrace{\int_{-\pi}^{\pi} f_{u}(\omega) d \omega}_{\hat{\sigma}^{2}}
\end{aligned}
$$

which allows to judge the importance of the phase shift.

\section{A.4 Gibbs sampler}

This section briefly sketches the Gibbs sampling algorithm. A more detailed explanation of the different sampling steps can be found in Primiceri (2005).

\section{A.4.1 Step 1: Initialization}

Initialize $\boldsymbol{A}^{T}, \boldsymbol{B}^{T}, \boldsymbol{\Sigma}^{T}$ and the hyperparameters $Q, W, S$. 


\section{A.4.2 Step 2: Drawing coefficient states $B^{T}$}

Conditional on the data and all other parameters the observation equation 10 is linear and has Gaussian innovations. $\boldsymbol{B}^{T}$ is sampled from $p\left(\boldsymbol{B}^{T} \mid \boldsymbol{y}^{T}, \boldsymbol{A}^{T}, \boldsymbol{\Sigma}^{T}, Q, W, S\right)$. Based on the algorithm of Carter and Kohn (1994) draws for $\boldsymbol{B}_{t}=\boldsymbol{B}_{t-1}+\nu_{t}$ are obtained from $p\left(\boldsymbol{B}^{T} \mid \boldsymbol{y}^{T}, \boldsymbol{A}^{T}, \boldsymbol{\Sigma}^{T}, Q, W, S\right)$, which is $N\left(\boldsymbol{B}_{t \mid t+1}, \boldsymbol{P}_{t \mid t+1}\right)$, with $\boldsymbol{B}_{t \mid t+1}=E\left(\boldsymbol{B}_{t} \mid \boldsymbol{B}_{t+1}, \boldsymbol{y}^{T}, \boldsymbol{A}^{T}, \boldsymbol{\Sigma}^{T}, Q, W, S\right)$ and $\boldsymbol{P}_{t \mid t+1}=\operatorname{Var}\left(\boldsymbol{B}_{t} \mid \boldsymbol{B}_{t+1}, \boldsymbol{y}^{T}, \boldsymbol{A}^{T}, \boldsymbol{\Sigma}^{T}, Q, W, S\right)$. $\boldsymbol{B}_{t \mid t+1}$ and $\boldsymbol{P}_{t \mid t+1}$ are calculated using the forward filtering, backward sampling (FFBS) algorithm.

\section{A.4.3 Step 3: Drawing covariance states $A^{T}$}

Together equation 10 and $\boldsymbol{X}_{t}^{\prime}=\boldsymbol{I}_{n} \otimes\left[1, \boldsymbol{y}_{t-1}^{\prime}, \boldsymbol{y}_{t-2}^{\prime}, \ldots, \boldsymbol{y}_{t-p}^{\prime}\right]$ can be rewritten as $\boldsymbol{A}_{t}\left(\boldsymbol{y}_{t}-\right.$ $\left.\boldsymbol{X}_{t}^{\prime} \boldsymbol{B}_{t}\right)=\boldsymbol{A}_{t} \hat{\boldsymbol{y}}_{t}=\boldsymbol{\Sigma}_{t} \boldsymbol{\epsilon}_{t}$, where, given $\boldsymbol{B}^{T}, \hat{\boldsymbol{y}}_{t}$ is observable. Under the assumption that $S$ is block-diagonal the ? ) algorithm can be used again to draw $\alpha_{i, t}$ from $N\left(\alpha_{i, t \mid t+1}, \Lambda_{i, t \mid t+1}\right)$, where $\alpha_{i, t \mid t+1}=E\left(\alpha_{i, t} \mid \alpha_{i, t \mid t+1}, \boldsymbol{y}^{T}, \boldsymbol{A}^{T}, \boldsymbol{\Sigma}^{T}, Q, W, S\right)$ and $\Lambda_{i, t \mid t+1}=\operatorname{Var}\left(\alpha_{i, t} \mid \alpha_{i, t \mid t+1}\right.$, $\left.\boldsymbol{y}^{T}, \boldsymbol{A}^{T}, \boldsymbol{\Sigma}^{T}, Q, W, S\right)$. See Primiceri (2005) for a discussion on the problem of nonlinearity and the assumption on $S$ in drawing $\boldsymbol{A}^{T}$.

\section{A.4.4 Step 4: Drawing volatility states $\Sigma^{T}$}

In a next step we consider $\boldsymbol{A}_{t}\left(\boldsymbol{y}_{t}-\boldsymbol{X}_{t}^{\prime} \boldsymbol{B}_{t}\right)=\boldsymbol{y}_{t}^{*}=\boldsymbol{\Sigma}_{t} \boldsymbol{\epsilon}_{t}$. Now, given $\boldsymbol{A}^{T}$ and $\boldsymbol{B}^{T}, \boldsymbol{y}_{t}^{*}$ can be observed. Squaring and taking logs transforms this system of equations into a linear one: $\boldsymbol{y}^{* *}=2 \boldsymbol{h}_{t}+\boldsymbol{e}_{t}$ with $\boldsymbol{h}_{t}=\boldsymbol{h}_{t-1}+\boldsymbol{\eta}_{t}$, where $y_{i, t}^{* *}=\log \left(\left(y_{i, t}^{*}\right)^{2}+\bar{c}\right), \bar{c}=0.001$ is an offset constant that makes the estimation procedure more robust, $e_{i, t}=\log \left(\epsilon_{i, t}^{2}\right)$, $h_{i, t}=\log \left(\sigma_{i, t}\right)$. Although, the system is now linear, its innovations are non-Gaussian since the errors are $\sim \log \chi^{2}(1)$. Following Kim et al. (1998) we use a mixture of seven normal densities for each element of $\boldsymbol{e}$. The seven normal densities have component probabilities $q_{j}$, means $m_{j}-1.2704$ and variances $v_{j}^{2}$, with $j=1, \ldots, 7$. If we define $s^{T}=\left[s_{1}, \ldots, s_{T}\right]^{\prime}$ to be the matrix of indicator variables that select for each element of $\boldsymbol{e}_{t}$ the respective member of the mixture, conditional on $\boldsymbol{B}^{T}, \boldsymbol{A}^{T}, Q, W, S$ and $s^{T}$ the system is now linear and approximately Gaussian. Thus, the Carter and Kohn (1994) algorithm can be used again to recursively draw the volatilities $\boldsymbol{h}_{t}$ from $N\left(\boldsymbol{h}_{t \mid t+1}, \boldsymbol{H}_{t \mid t+1}\right)$, with $\boldsymbol{h}_{t \mid t+1}=$ $E\left(\boldsymbol{h}_{t} \mid \boldsymbol{h}_{t+1}, \boldsymbol{y}^{T}, \boldsymbol{A}^{T}, \boldsymbol{B}^{T}, Q, W, S, s^{T}\right)$ and $\boldsymbol{H}_{t \mid t+1}=\operatorname{Var}\left(\boldsymbol{h}_{t} \mid \boldsymbol{h}_{t+1}, \boldsymbol{y}^{T}, \boldsymbol{A}^{T}, \boldsymbol{B}^{T}, Q, W, S, s^{T}\right)$. 


\begin{tabular}{cccc}
\hline \hline$j$ & $q_{j}$ & $m_{j}$ & $v_{j}^{2}$ \\
\hline 1 & 0.0073 & -10.12999 & 5.79596 \\
2 & 0.10556 & -3.97281 & 2.61369 \\
3 & 0.00002 & -8.56686 & 5.17950 \\
4 & 0.04395 & 2.77786 & 0.16735 \\
5 & 0.34001 & 0.61942 & 0.64009 \\
6 & 0.24566 & 1.79518 & 0.34023 \\
7 & 0.25750 & -1.08819 & 1.26261 \\
\hline
\end{tabular}

Table 2: Mixing Distributions as in Kim et al. (1998)

\section{A.4.5 Step 5: Drawing hyperparameters $Q, W$ and $S$}

Conditional on $\boldsymbol{y}^{T}, \boldsymbol{B}^{T}, \boldsymbol{A}^{T}$ and $\boldsymbol{\Sigma}^{T}$ the hyperparameters $Q, W$ and $S$ can be obtained directly from their inverse-Wishart posterior distributions.

\section{A.4.6 Step 6: Sampling replications}

Go back to Step 2. 


\section{A.5 Impulse responses and FEVD}
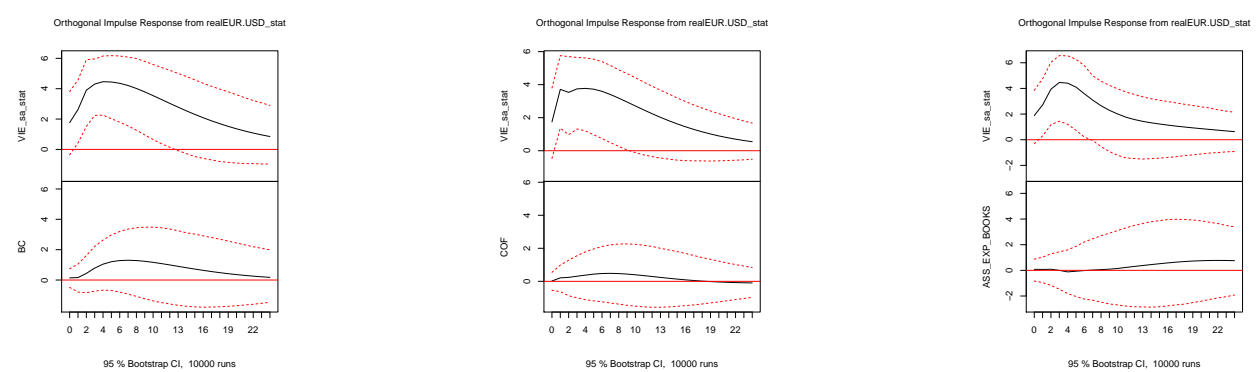

Figure 2: Impulse responses of EXP and respective climate indicator for orthogonal shock in EXR (HP-filtered series)
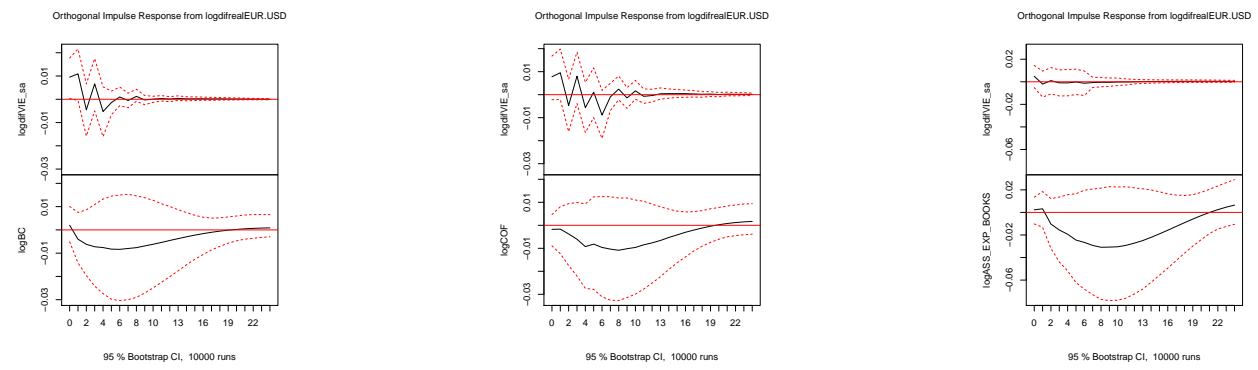

Figure 3: Impulse responses of EXP and respective climate indicator for orthogonal shock in EXR ( $\log \mathrm{D}$-filtered series) 

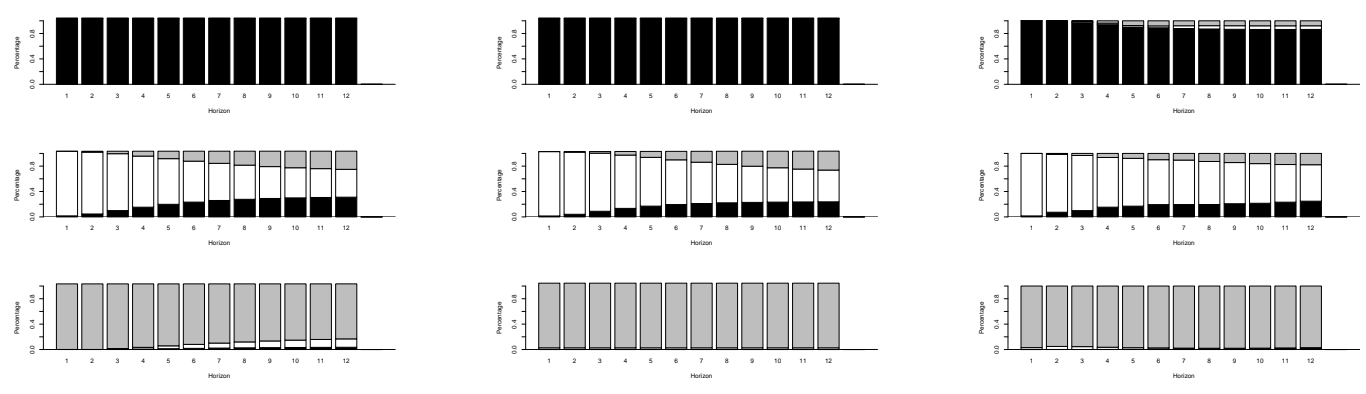

Figure 4: FEVD for EXR, EXP and respective climate indicator (HP)
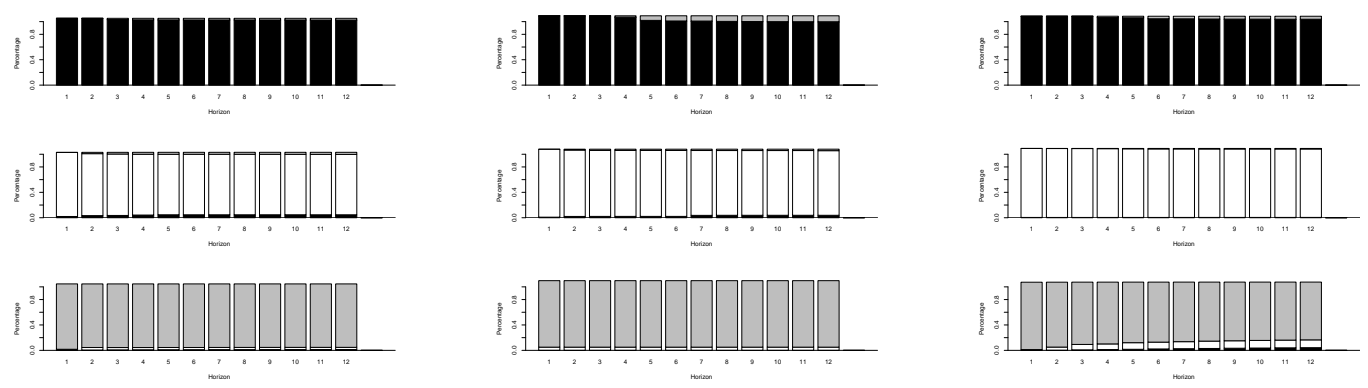

Figure 5: FEVD for EXR, EXP and respective BC indicator $(\log \mathrm{D})$ 

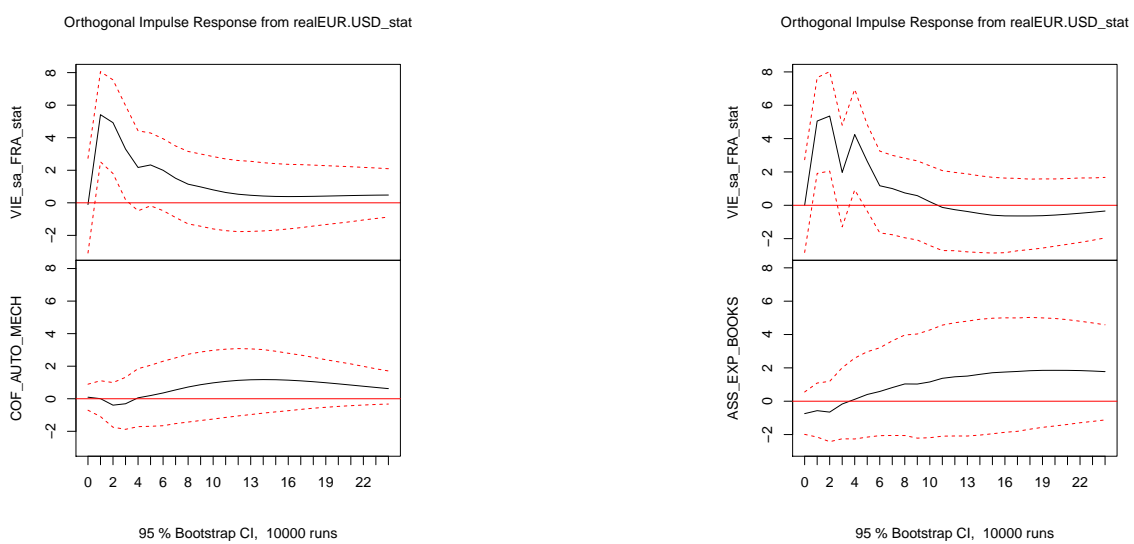

Figure 6: Impulse responses of EXP and respective climate indicator for orthogonal shock in EXR (HP): France
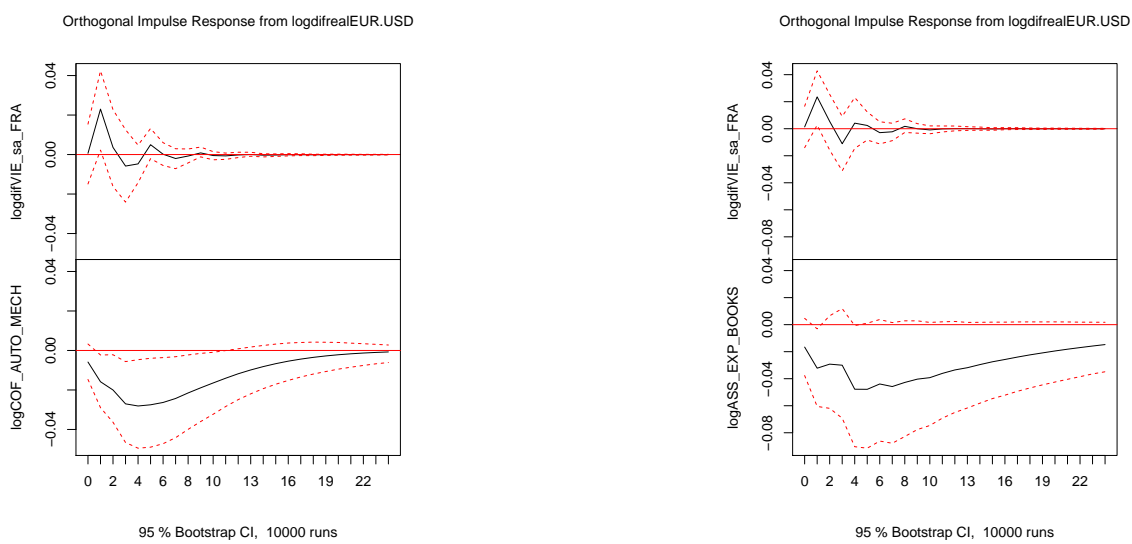

Figure 7: Impulse responses of EXP and respective BC indicator for orthogonal shock in EXR $(\log \mathrm{D})$ : France 

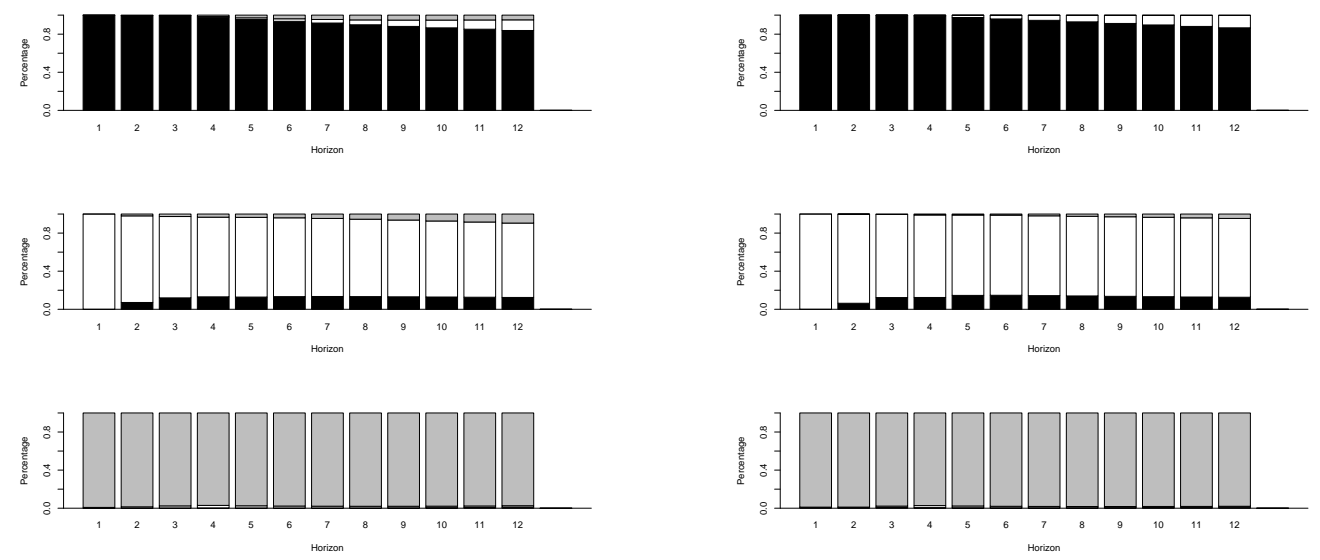

Figure 8: FEVD for EXR, EXP and respective climate indicator (HP): France
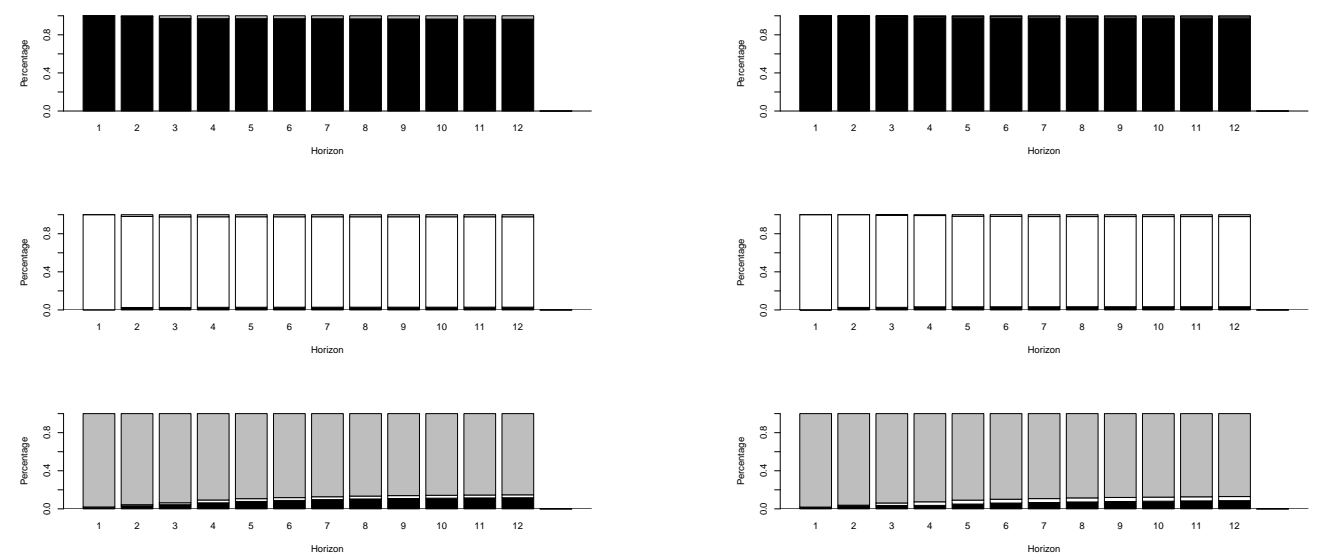

Figure 9: FEVD for EXR, EXP and respective climate indicator $(\log \mathrm{D})$ : France 

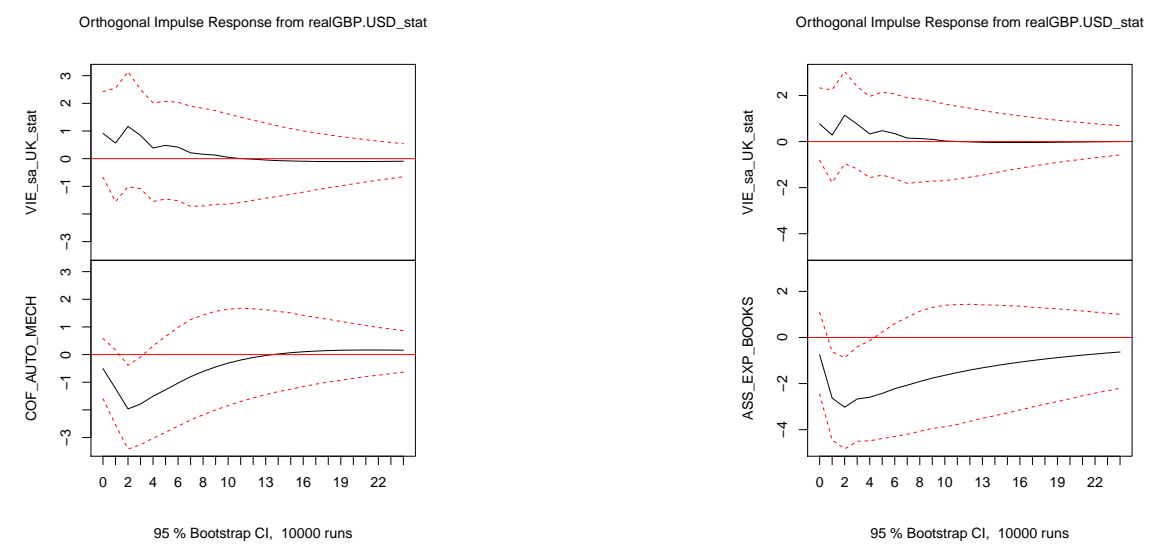

Figure 10: Impulse responses of EXP and respective climate indicator for orthogonal shock in EXR (HP): UK
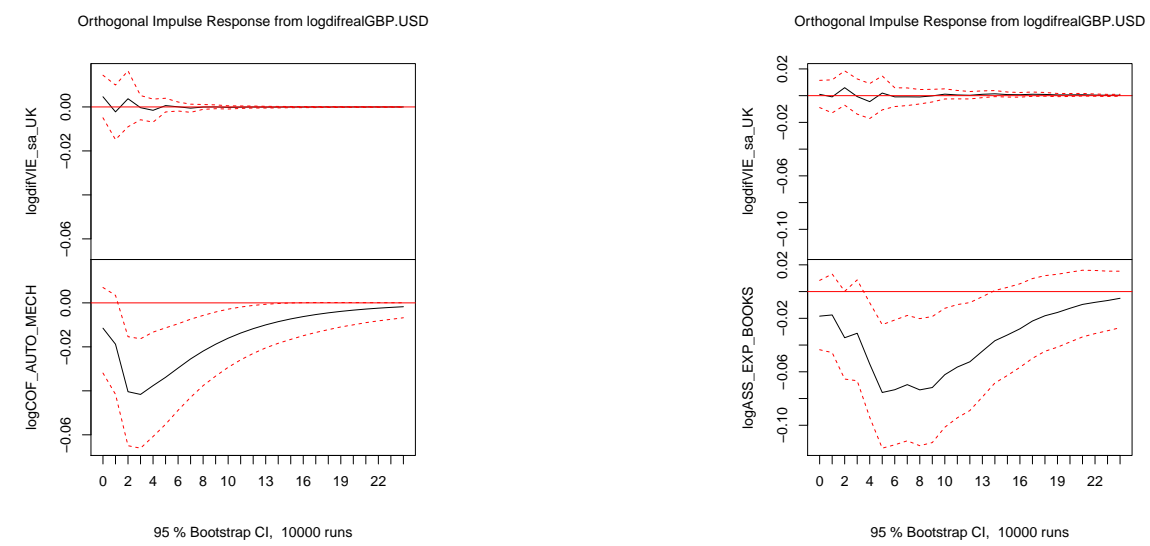

Figure 11: Impulse responses of EXP and respective climate indicator for orthogonal shock in EXR $(\log \mathrm{D})$ : UK 

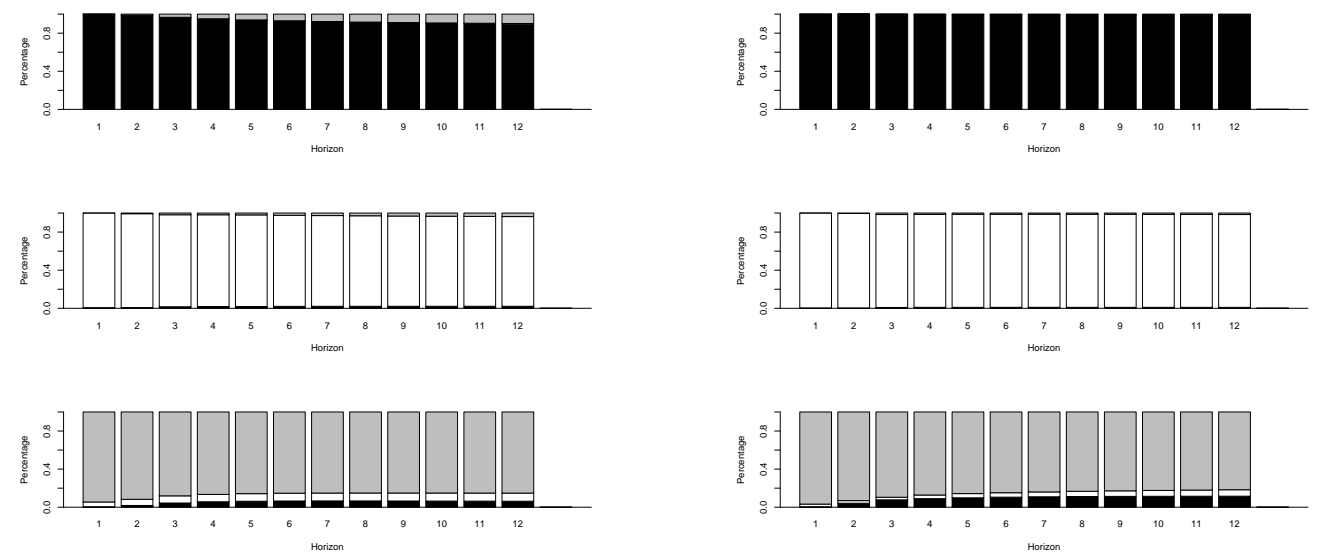

Figure 12: FEVD for EXR, EXP and respective climate indicator (HP): UK
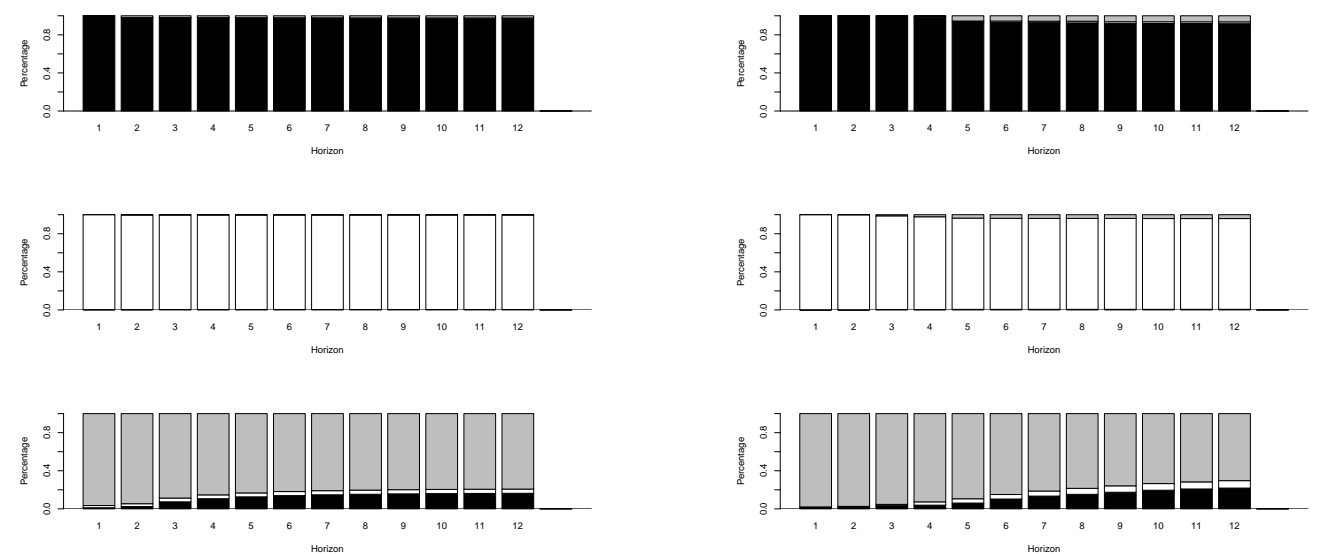

Figure 13: FEVD for EXR, EXP and respective climate indicator (logD): UK 


\section{A.6 Estimation results}

Endogenous variables: EXR, EXP, BC

Deterministic variables: const

Method: Ordinary Least Squares

Sample: Jan1995 Oct2010

Sample size: 187

Log Likelihood: -806.912

\begin{tabular}{|c|c|c|c|c|}
\hline \multicolumn{5}{|c|}{$\begin{array}{l}\text { Equation: } E X R=E X R . l 1+E X P . l 1+B C . l 1+E X R . l 2+E X P . l 2+B C . l 2+E X R . l 3 \\
+E X P . l 3+B C . l 3+\text { const }\end{array}$} \\
\hline \multicolumn{5}{|c|}{ Coefficient Std. Error } \\
\hline \multicolumn{5}{|c|}{$7.494 e-02$} \\
\hline EXP.11 & $1.438 e-04$ & $1.067 e-04$ & 1.347 & 0.1796 \\
\hline BC.11 & $-3.613 e-05$ & $3.380 e-04$ & -0.107 & 0.9150 \\
\hline EXR.12 & $-5.535 e-01$ & $1.149 e-01$ & -4.815 & $3.14 e-06^{* * *}$ \\
\hline EXP.12 & $1.445 e-04$ & $1.091 e-04$ & 1.324 & 0.1871 \\
\hline BC.12 & $-6.117 e-04$ & $4.868 e-04$ & $4.868 e-04$ & 0.2106 \\
\hline EXR.13 & $1.569 e-01$ & $7.582 e-02$ & 2.070 & $0.0399 *$ \\
\hline EXP.13 & $-1.234 e-04$ & $1.084 e-04$ & -1.138 & 0.2566 \\
\hline BC.13 & $4.566 e-04$ & $3.392 e-04$ & 1.346 & 0.1799 \\
\hline const & $3.582 e-04$ & $1.464 e-03$ & 0.245 & 0.8070 \\
\hline \multirow{2}{*}{$\begin{array}{l}\text { Multiple R-squared } \\
\text { F-statistic }\end{array}$} & 0.8975 & \multirow[t]{2}{*}{ Adj } & R-squared & 0.8923 \\
\hline & 172.2 on 9 and $177 \mathrm{DF}$ & & p-value & $<2.2 \mathrm{e}-16$ \\
\hline
\end{tabular}

Table 3: Estimation Results VAR[3]-Model 


\begin{tabular}{|c|c|c|c|c|}
\hline \multicolumn{5}{|c|}{$\begin{array}{l}\text { Equation: } E X P=E X R . l 1+E X P . l 1+B C . l 1+E X R . l 2+E X P . l 2+B C . l 2+E X R . l 3 \\
+E X P . l 3+B C . l 3+\text { const }\end{array}$} \\
\hline Variable & Coefficient & Std. Error & t-Statistic & Prob. \\
\hline EXR.11 & $1.637 e+02$ & $5.314 e+01$ & 3.080 & $0.002399 * *$ \\
\hline EXP.11 & $2.858 e-01$ & $7.568 e-02$ & 3.777 & $0.000217^{* * *}$ \\
\hline BC.11 & $4.932 e-01$ & $2.397 e-01$ & 2.058 & $0.041070^{*}$ \\
\hline EXR.12 & $-1.018 e+02$ & $8.151 e+01$ & -1.249 & 0.213151 \\
\hline EXP.12 & $2.234 e-01$ & $7.737 e-02$ & 2.887 & $0.004374^{* *}$ \\
\hline BC.12 & $-3.598 e-02$ & $3.452 e-01$ & -0.104 & 0.917115 \\
\hline EXR.13 & $3.624 e+01$ & $5.377 e+01$ & 0.674 & 0.501174 \\
\hline EXP.13 & $7.433 e-03$ & $7.688 e-02$ & 0.097 & 0.923089 \\
\hline BC.13 & $-5.433 e-02$ & $2.405 e-01$ & -0.226 & 0.821541 \\
\hline const & $-7.250 e-01$ & $1.038 e+00$ & -0.698 & 0.485860 \\
\hline Multiple R-squared & 0.6426 & Adj. & R-squared & 0.6244 \\
\hline F-statistic & 35.36 on 9 and $177 \mathrm{DF}$ & & p-value & $<2.2 \mathrm{e}-16$ \\
\hline
\end{tabular}

Equation: $B C=E X$ R.l1
$+E X X P . l 3+B C . l 3+$ const

Table 4: Estimation Results VAR[3]-Model cont'ed 
Endogenous variables: EXR, EXP, BC

Deterministic variables: const

Method: Ordinary Least Squares

Sample: Jan1995 Oct2010

Sample size: 187

Log Likelihood: -817.391

\begin{tabular}{lrrrr}
\hline \multicolumn{1}{c}{ Equation: $E X R=E X R . l 1+E X R . l 2+E X R . l 3$} \\
\hline Variable & Coefficient & Std. Error & t-Statistic & Prob. \\
\hline EXR.11 & 1.31033 & 0.07320 & 17.901 & $<2 e-16^{* * *}$ \\
EXR.12 & -0.53173 & 0.11495 & -4.626 & $7.02 e-06^{* * *}$ \\
EXR.13 & 0.14730 & 0.07324 & 2.011 & $0.0457^{*}$ \\
\hline Multiple R-Squared & 0.8924 & Adjusted R-squared & 0.8907 \\
F-statistic & 508.8 on 3 and 184 DF & & p-value & $<2.2 \mathrm{e}-16$ \\
\hline
\end{tabular}

Equation: $E X P=E X R . l 1+E X P . l 1+B C . l 1+E X P . l 2$

\begin{tabular}{lrrrr}
\hline Variable & Coefficient & Std. Error & t-Statistic & Prob. \\
\hline EXR.11 & 102.54018 & 22.34386 & 4.589 & $8.24 e-06^{* * *}$ \\
EXP.11 & 0.28481 & 0.07148 & 3.985 & $9.75 e-05^{* * *}$ \\
BC.11 & 0.41549 & 0.07809 & 5.321 & $3.00 e-07^{* * *}$ \\
EXP.12 & 0.21449 & 0.06836 & 3.138 & $0.00198^{* *}$ \\
\hline Multiple R-Squared & 0.6376 & Adjusted R-squared & 0.6297 \\
F-statistic & 80.5 on 4 and 183 DF & & p-value & $<2.2 \mathrm{e}-16$ \\
\hline
\end{tabular}

Equation: $B C=B C . l 1+E X R . l 2+E X P . l 2+B C . l 3$

\begin{tabular}{lrrrr}
\hline Variable & Coefficient & Std. Error & t-Statistic & Prob. \\
\hline BC.11 & 1.15062 & 0.04566 & 25.198 & $<2 e-16^{* * *}$ \\
EXR.12 & 18.87177 & 6.74269 & 2.799 & $0.005678^{* *}$ \\
EXP.12 & -0.07381 & 0.02065 & -3.575 & $0.000448^{* * *}$ \\
BC.13 & -0.13906 & 0.05005 & -2.778 & $0.006036^{* *}$ \\
\hline Multiple R-Squared & 0.945 & Adjusted R-squared & 0.9438 \\
F-statistic & 786.6 on 4 and 183 DF & & p-value & $<2.2 \mathrm{e}-16$ \\
\hline
\end{tabular}

Table 5: Estimation Results Subset VAR[3]-Model 